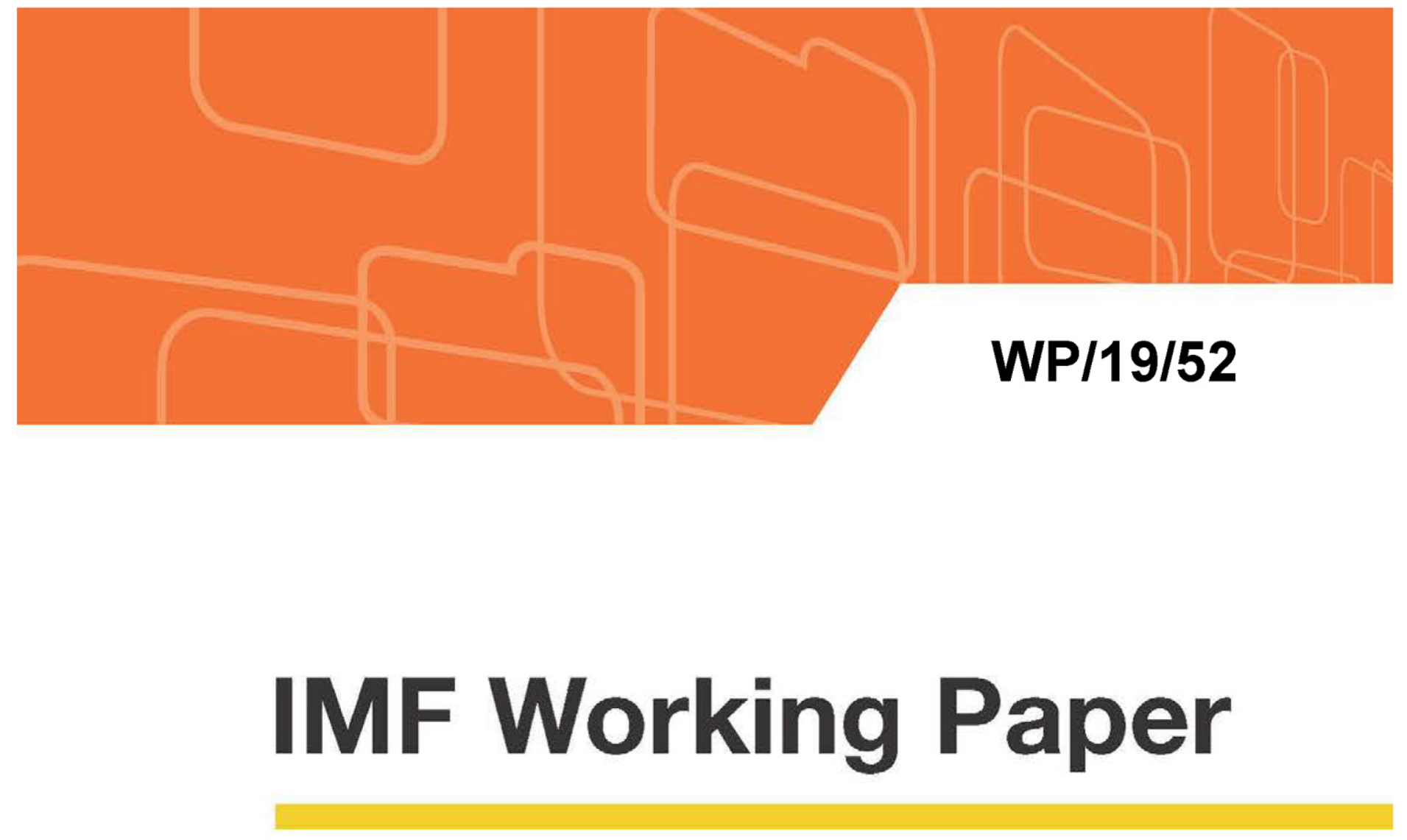

\title{
Determinants of Currency Composition of Reserves: a Portfolio Theory Approach with an Application to RMB
}

by Yinqiu Lu and Yilin Wang

IMF Working Papers describe research in progress by the author(s) and are published to elicit comments and to encourage debate. The views expressed in IMF Working Papers are those of the author(s) and do not necessarily represent the views of the IMF, its Executive Board, or IMF management. 


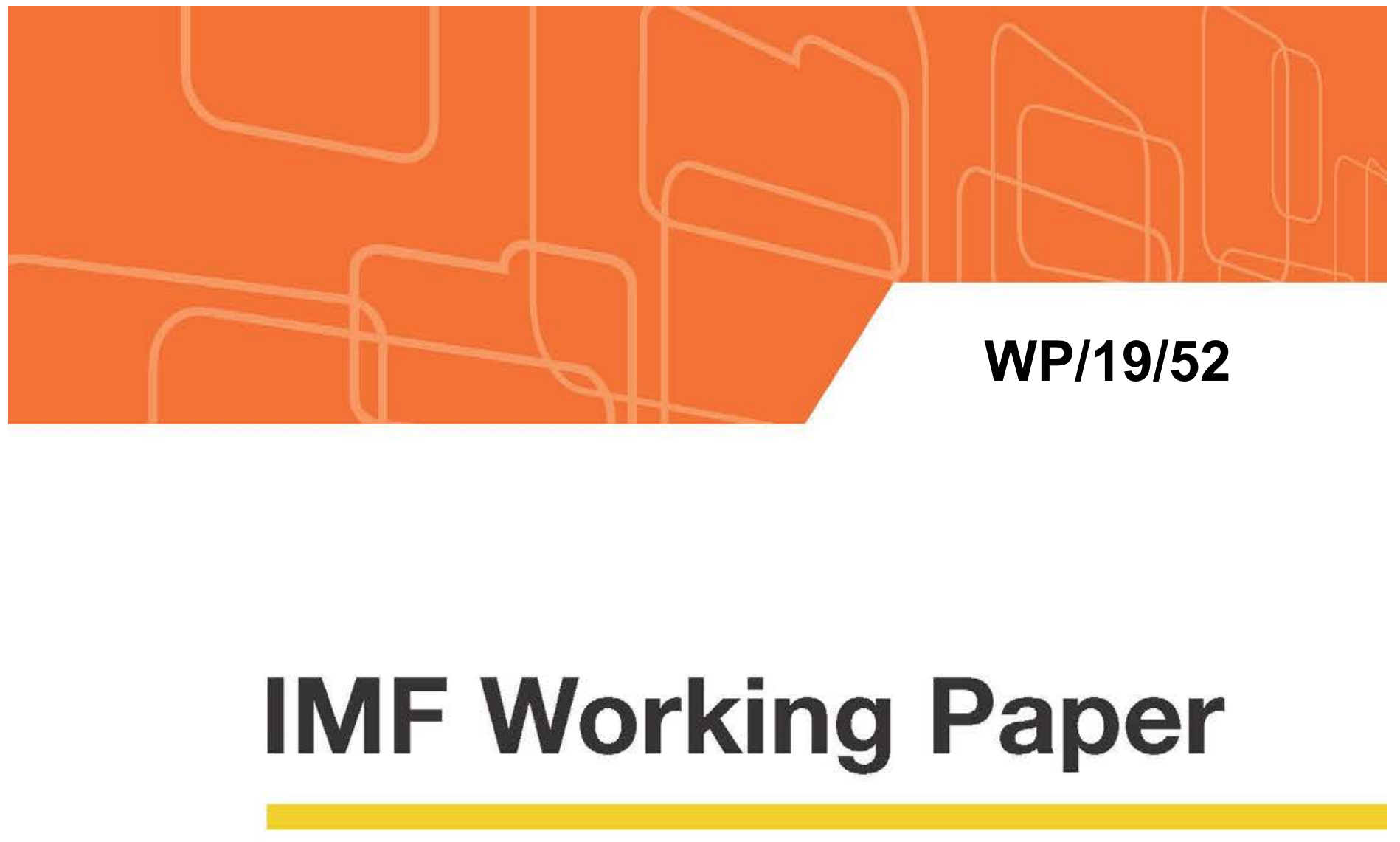

\section{Determinants of Currency Composition of Reserves: a Portfolio Theory Approach with an Application to RMB}

by Yinqiu Lu and Yilin Wang

IMF Working Papers describe research in progress by the author(s) and are published to elicit comments and to encourage debate. The views expressed in IMF Working Papers are those of the author(s) and do not necessarily represent the views of the IMF, its Executive Board, or IMF management.

$$
\text { I N T ER N A T I O N A L M O NETAR Y FU N D }
$$




\title{
IMF Working Paper
}

Strategy, Policy, and Review Department

\section{Determinants of Currency Composition of Reserves: a Portfolio Theory Approach with an Application to RMB}

Authorized for distribution by Martin Kaufman ${ }^{1}$

March 2019

\begin{abstract}
IMF Working Papers describe research in progress by the author(s) and are published to elicit comments and to encourage debate. The views expressed in IMF Working Papers are those of the author(s) and do not necessarily represent the views of the IMF, its Executive Board, or IMF management.
\end{abstract}

\begin{abstract}
The way central banks manage their foreign reserve assets has evolved over the past decades. One major trend is managing reserves in two or more tranches - liquidity tranche and investment tranche - especially for those with adequate reserves. Incorporating reserve tranching, we have developed in this paper a central bank's reserve portfolio choice model to analyze the determinants of the currency composition of reserves. In particular, we adopt the classical mean-variance framework for the investment tranche and the asset-liability framework for the liquidity tranche. Building on these frameworks, the roles of currency compositions in imports invoicing and short-term external debt, and risk and returns of reserve currencies can be quantified by our structural model—a key contribution of our paper given the absence of structural models in the literature. Finally, we estimate the potential paths of the share of RMB in reserves under different scenarios to shed light on its status as an international currency.
\end{abstract}

JEL Classification Numbers: C58; F37; G11; G17

Keywords: currency composition; FX reserves; portfolio theory; RMB

Author's E-Mail Address: ylu@imf.org; wangyilin@g.ucla.edu

\footnotetext{
${ }^{1}$ This paper has benefitted from comments from Varapat Chensavasdijai, Sean Craig, James Daniel, Pragyan Deb, Luciana Juvenal, Martin Kaufman, and Asad Qureshi. We remain responsible for any remaining errors.
} 


\section{Contents}

1 Introduction $\quad \underline{4}$

2 Literature Review $\quad \underline{7}$

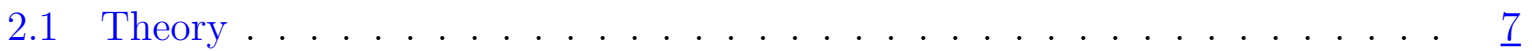

2.2 Empirical evidence . . . . . . . . . . . . . . . . . . $\underline{7}$

2.3 Survey and case studies . . . . . . . . . . . . . . . . . . . $\underline{9}$

3 Stylized Patterns and Evidence from a Reduced-form Regression $\quad \underline{10}$

3.1 Currency compositions of FX reserves, external debt, and imports invoicing $\underline{10}$

3.2 Domestic currency as numeraire . . . . . . . . . . . . . . . 12

3.3 Exchange rate risk and interest rate risk . . . . . . . . . . . . 13

3.4 Evidence from a reduced-form regression . . . . . . . . . . . . $\underline{13}$

4 Data $\quad \underline{15}$

5 A Portfolio Choice Model $\quad \underline{18}$

6 Estimation $\quad \underline{22}$

6.1 Results.......................... . . . 22

6.2 The size of the liquidity tranche included in the reduced-form analysis . . . $\underline{27}$

7 The RMB as Reserve Currency $\quad \underline{28}$

7.1 The liquidity of the government bond market and the convertibility of the

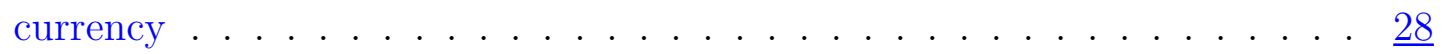

7.2 The RMB as reserve currency under different scenarios . . . . . . . . . 30

8 Conclusion $3 \underline{33}$ 


\section{Introduction}

This paper applies a portfolio theory approach to analyze the determinants of the currency composition of foreign exchange (FX) reserves. Even though the need for reserves varies by country, the majority of central banks manage their reserves in a similar approach with common features including:

- Central banks are in general highly risk-averse, with the bulk of their reserves invested in safe assets. ${ }^{1}$

- Central banks often follow a portfolio optimization strategy (RBS, 2003 and 2005; ECB, 2004) with the mean-variance portfolio diversification approach being a popular one (Reddy, 2003; De Leon, 2003; and Naameh, 2003). ${ }^{2}$

- "Safety, liquidity, and profitability" are generally accepted as the objectives of reserve management (Nugee, 2000; and IMF, 2001) with safety and liquidity being the primary goals (Borio et al., 2008).

- Central banks often create a "liquidity tranche" portfolio and a "investment portfolio". The liquidity tranche is designed to finance the day-to-day FX needs, facilitating trade and financial flows. ${ }^{3}$ Its asset portfolio often includes exclusively T-bills and time deposits. The "investment portfolio" pursues the highest return subject to risk constraints. ${ }^{4}$ It is especially relevant for countries with large reserve holdings that can afford to invest with longer-term growth objectives. ${ }^{5}$ Two-thirds of the central banks responding to a BIS survey had established two (or more) separate

\footnotetext{
${ }^{1}$ For example, in the case of Canada, the list of eligible reserves currencies is limited to US dollars, euros, Japanese yen, and UK pounds; and the list of eligible asset classes is similarly narrow and limited to fixed-income securities (Merkowsky and Wolfe, 2015).

${ }^{2}$ Central banks have followed the broad trend of the asset management sector of the financial industry, borrowing and putting in place very much the same kind of processes and tools (Borio et al., 2008).

${ }^{3}$ For example, in the case of Israel, "About three quarters of the reserve portfolio is invested in very liquid assets. The other quarter is invested in assets with slightly lower liquidity. The ratio is set in relation to the level of reserves and an assessment of the possible need for liquidity." (Boorman and Ingves, 2001).

${ }^{4}$ For example, in the case of Chile, "The diversification portfolio is managed on the basis of a risk budget. This risk budget controls exchange rate risk, interest risk and, partly, credit risk."

${ }^{5}$ For example, the investment portfolio of Hong Kong SAR is invested to preserve the Fund's value for future generations (Boorman and Ingves, 2001).
}

CInternational Monetary Fund. Not for Redistribution 
tranches (Borio et al., 2008). The size of each tranche differs by central bank. In some cases, less than 10 percent of reserves are allocated to liquidity tranche, while in others, over half of reserves are held in this tranche.

- The currency compositions of imports invoicing and short-term external debt could have a significant effect on the currency composition of FX reserves. If reserves are considered mainly as providing an insurance (a "hedge") against the loss of accesss to foreign goods and services, the currency composition of import basket is relevant for the currency composition of reserves. If reserves are seen as primarily hedging against the loss of the access to international financial markets, the currency composition of external liabilities would be more relevant (Borio et al., 2008). ${ }^{6}$ Some well-known rules of thumb, such as the ratio of reserves to imports or the ratio of reserves to short-term external liabilities, have been used to assess the adequate level of reserves.

- A shift towards using domestic currency as numeraire (i.e., to serve as a unit of account) may well have taken place (Borio et al., 2008, McCauley, 2008; Riksbank, 2006; and the Central Bank of Chile, 2006).

Incorporating these features into consideration, we introduce a central bank's reserve portfolio choice model. Our approach adopts the classical mean-variance framework for the investment tranche; while the asset-liability framework is adopted for the liquidity tranche. As pointed out by Sharpe and Tint (1990), the asset-liability framework is appropriate in cases where the types of liabilities are very different (such as FX obligations arising from imports and debt payments). ${ }^{7}$ As shown later, the asset-liability framework can deliver a closed-form solution, which makes parameter estimations convenient. Our structural model enables us to quantify the importance of various factors in influencing a central bank's decision.

\footnotetext{
${ }^{6}$ As noted in Boorman and Ingves (2001), in the case of Columbia, "The authorities are now also considering bringing the currency composition of reserves closer in line with that of the stock of short-term external debt"; in the case of Israel, "The benchmark comprises pre-set weights of several currencies, determined more or less in accordance with the currency composition of imports and debt service expenditure in the coming year"; and in the case of Korea, "currency composition is based on the currency of external debt, current payments and market depth and size of reserve assets."

${ }^{7}$ The original Markowitz model (Markowitz, 1952) is a special case of the asset-liability model.
}

CInternational Monetary Fund. Not for Redistribution 
Using the IMF Currency Composition of Official Foreign (COFER) data, we can quantify the roles of the currency compositions of imports invoicing and short-term external debt, and risk and returns of reserve currencies in determining the currency composition of FX reserves. We can also estimate the likely paths of RMB's share in FX reserves under different scenarios.

Given the absence of structural models in the literature, a key contribution of our paper is to quantify the importance of various factors in determining the currency composition of FX reserves by using a structural model that explicitly models central banks' multitranche optimization problem, in particular, at the aggregate level of central banks. Prior to our work, the importance of these factors in determining the currency composition at the aggregate level of central banks was recognized largely qualitatively, and was estimated by some using reduced-form approaches. Our structural approach complements them and has the advantage of identifying the mechanisms that determine the outcomes of currency composition and relating them to central banks' preferences and other factors. In addition, the structural model can conduct counter-factual analyses and scenario-based forecasts.

The remainder of the paper is organized as follows. Section 2 reviews the literature. Section 3 introduces the stylized patterns of reserves and reserve management, and presents an analysis based on a reduced-form regression. Section 4 describes the data. Section 5 proposes our portfolio choice model for central banks. Section 6 illustrates our estimation strategy and presents results. Section 7 analyzes the paths of the share of RMB in FX reserves under different scenarios. ${ }^{8}$ Section 8 concludes.

\footnotetext{
${ }^{8}$ There are many types of reserve buyers, including central banks, private banks, and investment managers. However due to the importance of central banks as reserve buyers, "shares in central banks' foreign exchange reserve holdings are the most important measure of international currency status as well as the most easily measured." (Frankel, 2012)
} 


\section{Literature Review}

\subsection{Theory}

There is a set of literature that focuses on the modeling of the internationalization of one currency. Krugman (1984) shows how there can be multiple equilibrium in the use of an international currency. Kiyotaki et al. (1993) develops a theory of random matching games. Rey (2001) shows that the possibility of multiple equilibrium in the internationalization of currencies is determined by network externalities and the pattern of international trade. Gourinchas et al. (2010) presents a model of the special "exorbitant privilege" role of the US dollar in the international financial system.

As reserve currency fulfills three roles-an international store of value, a unit of account, and a medium of exchange (Krugman, 1984, and Frankel, 1992)-the literature on safe asset shortages and rollover risk is relevant. He et al. (2018) reviews this set of literature and links the determination of reserve asset status to the relative fundamentals and relative debt sizes by modeling two countries that issue sovereign bonds to satisfy reserve asset demands from investors.

\subsection{Empirical evidence}

Eichengreen (1998) applies a reduced-form analysis based on the annual aggregate-level FX reserve currency composition data (1971-1995). Its results indicate that a reservecurrency country's shares of global GDP and global trade have significant positive effect on that currency's share in global FX reserves.

Chinn and Frankel (2005) also uses the aggregate-level data (1973-1998) on the shares of seven main currencies in official reserve holdings to investigate the determinants of the currency composition of international reserves. Their main finding is that the lagged depreciation rate and inflation (or exchange rate volatility) have negative and significant influence on the share, while income having a significantly positive influence. ${ }^{9}$ They also

\footnotetext{
${ }^{9}$ They also find the shares of major currencies in global reserve holdings are very persistent (the coefficient on the lagged dependent variable is between 0.85 and 0.96). Fukuda and Ono (2005) builds an open economy model with monopolistic competition among firms that generates high inertia in the
}

(C) International Monetary Fund. Not for Redistribution 
point out that to attain international currency status, the currency issuing country's financial markets must be not only open and free of control but also deep and well developed.

Dooley et al. (1989), and Eichengreen and Mathieson (2000) use confidential IMF data on the country-level currency composition of reserve holdings. Both find that currency pegs, the direction of trade, and the currency of foreign debt are significant and robust determinants of the currency composition of reserve holdings; and their importance is stable across time. Dooley et al. (2003, and 2004) also point out that trade links and currency pegs are the key reasons behind the East Asian and Latin American central banks' unwillingness to follow a pure textbook diversification strategy. ${ }^{10}$

Papaioannou et al. (2006) proposes a theoretically grounded and simple mean-variance framework and modifies it to incorporate the specific needs of monetary authorities to hold a sizable portion of their holdings in the currencies of their external debt and the currencies of their main trading partners. Their results indicate that the optimum portfolios show a much lower weight for the euro than is observed. Zhang et al. (2012) assumes central banks have two sub-portfolios or tranches; one is with higher risk aversion and fulfills the safety and liquidity objectives and the other is oriented with lower risk aversion and fulfills the profitability objective. Fisher and Lie (2004) presents a strategic asset allocation framework and shows that with their assumption of the model's parameters, a typical central bank can significantly increase the efficiency of its portfolio by relaxing the constraints.

With respect to the estimates of RMB's share as reserve currency, Chen, Peng, and Shu (2011) uses a post-euro data set (1999-2006), and infers from the estimates that RMB could quickly attain the same international currency status as the yen and pound, ascurrency invoicing of exports. This provides an explanation for the dollar's dominant and stable role in invoicing international trade transactions. Since trade patterns affect the composition of FX reserves, this theory provides one explanation for the high persistence of the dollar in reserve holdings. As our model has taken the trade invoicing into consideration, we do not endogenize the inertia effect through other channel.

${ }^{10}$ The results in Papaioannou et al. (2006) suggest that even if the East Asian countries increase their trade with the euro zone and issue euro-denominated securities, as long as they peg their currencies to the dollar, it is very unlikely that they will massively diversify away from the dollar.

(C) International Monetary Fund. Not for Redistribution 
suming that China achieved full financial market development. Subramanian and Kessler (2013) forecasts the internalization of RMB from the perspective of reference currency. They show that RMB has increasingly become a reference currency due to trade integration. They forecast that a more global RMB bloc would emerge by the mid-2030s if trade were the sole driver.

\subsection{Survey and case studies}

Based on information from central bank asset managers as well as survey data on their reserve policies, Royal Bank of Scotland and the European Central Bank (RBS, 2003 and 2005; and ECB, 2004) note that central banks do follow a portfolio optimization strategy. The reviews by Reddy (2003) and De Leon (2003) of the asset management practices of the Indian and the Canadian central banks suggest that these institutions pursue mean-variance portfolio diversification policies in their main international reserve holdings. This is further emphasized in Naameh (2003)'s overview of developing countries' reserves management, which also presents evidence that constraints associated with trade, debt composition, and the currency peg are particularly important in deciding currency composition.

Borio et al. (2008) documents the reserve management practices of central banks. Their discussion relies on a survey of central banks and monetary authorities representing in total about 80 percent of global FX reserves at end-2006. They find safety and liquidity are still universally agreed to be the primary goals; at the same time, the weight on the return objectives has generally increased over time; while these trends are common to all central banks, practices still differ considerably, reflecting country-specific circumstances. 


\section{Stylized Patterns and Evidence from a Reduced- form Regression}

\subsection{Currency compositions of FX reserves, external debt, and imports invoicing}

Figure 1 shows the main emerging and developing countries' aggregate FX reserves in main reserve currencies (EUR, JPY, GBP, and USD), imports and short-term external debt denominated in these reserve currencies between 2006 Q1 and 2014 Q4. ${ }^{11}$ It shows a rapid accumulation of reserves.

Figure 1: FX Reserves, Imports Invoicing, and Short-term External Debt Denominated in EUR, JPY, GBP, and USD ( 2006 Q1 - 2014 Q4, in mln USD)

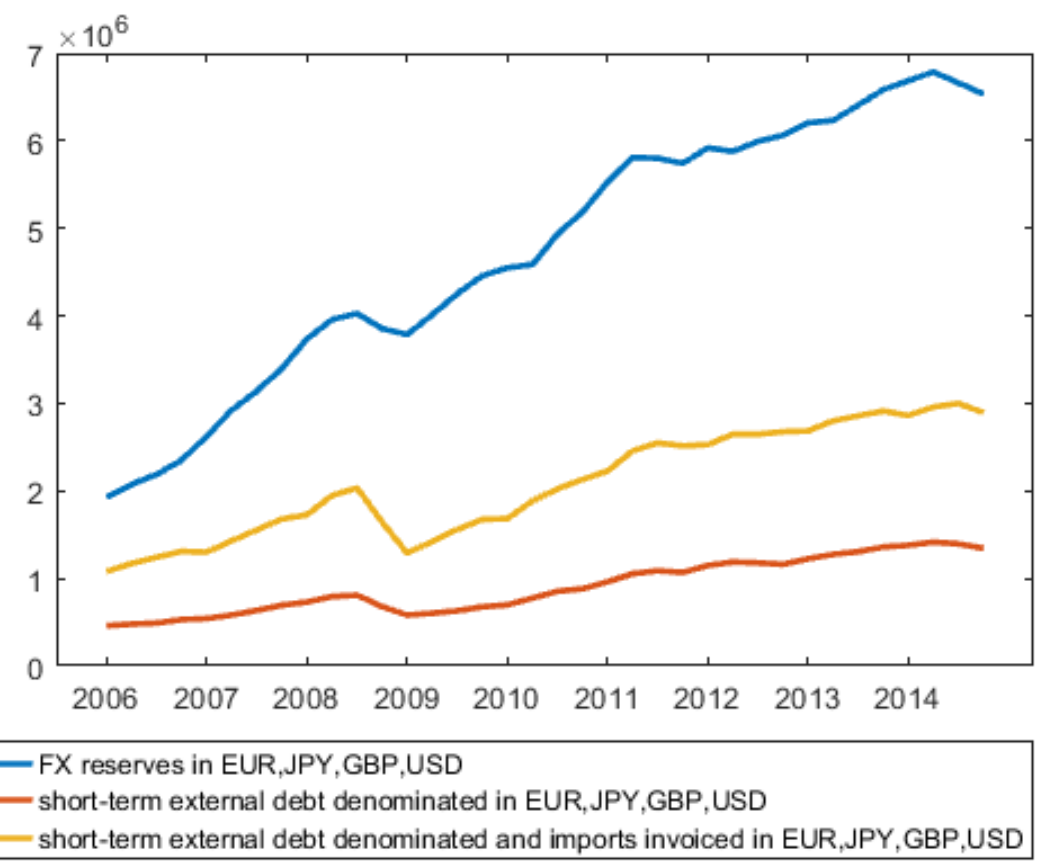

Sources: Federal Reserve Bank of St. Louis; Gopinath (2016); Haver; IMF COFER and DOTS;

UNCTAD; World Bank International Debt Statistics; and authors' calculations.

The shares of euro and dollar in import invoicing and external debt are moving in line with their shares in FX reserves (Figure 2). The shares of dollar in FX reserves and

\footnotetext{
${ }^{11}$ The data source and calculation are shown in Section 3.
}

10 
external debt have increased. Cross-sectional data also shows that the shares of of euro and dollar in external debt are in line with their shares in FX reserves (Figure 3).

Figure 2: The Shares of EUR and USD in FX Reserves, Imports Invoicing, and Short-term External Debt (2006 Q1 - 2014 Q4)
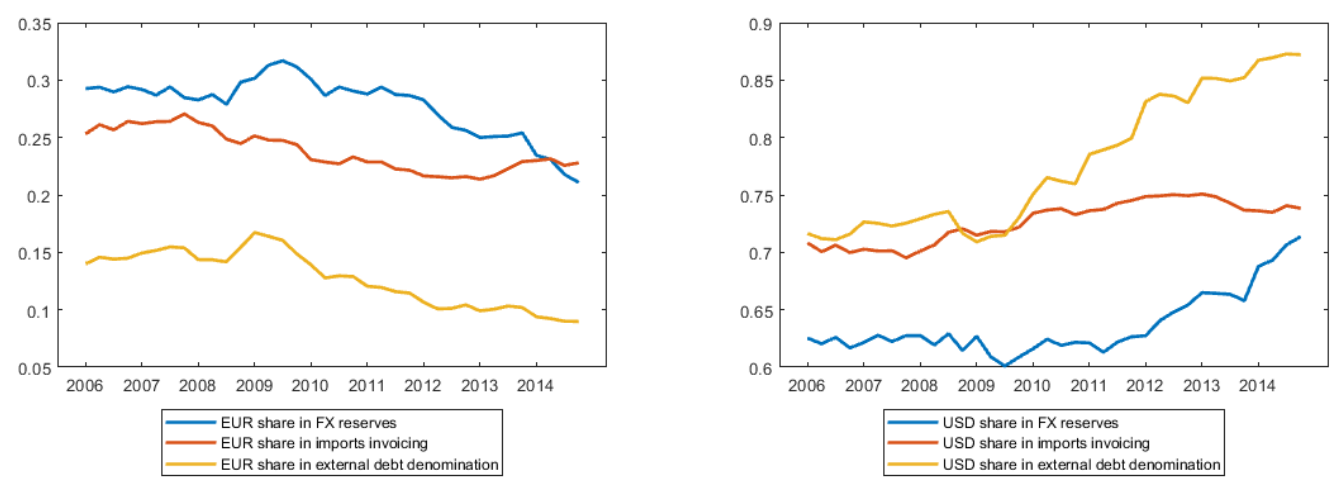

Sources: Gopinath (2016); Haver; IMF COFER and DOTS; UNCTAD; World Bank International Debt Statistics; and authors' calculations.

Figure 3: The Shares of EUR (left) and USD (right) in FX Reserves versus in External Debt (2016 Q4)
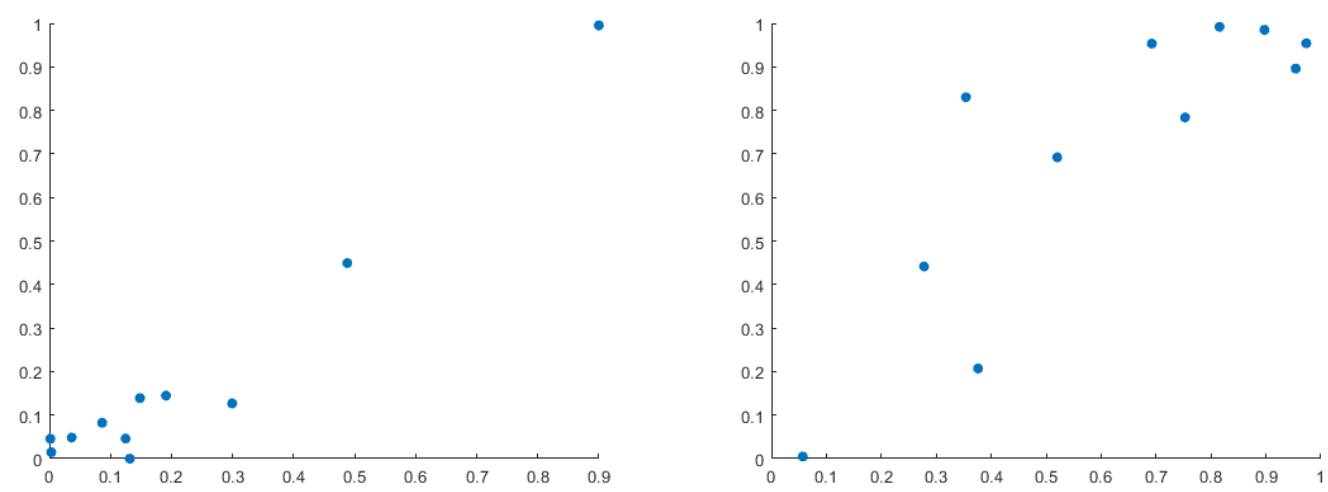

Sources: Haver; IMF COFER; World Bank International Debt Statistics; and authors' calculations. 


\subsection{Domestic currency as numeraire}

When central banks measure the risk and returns in reserve management, different numeraire choices would generally imply different optimal allocations. For example, if a domestic currency varies less against the dollar than other major currencies, a reserve portfolio with a substantial dollar share poses less risk when returns are measured in that domestic currency. The central banks in Australia (Vallence, 2012) and Chile (Central Bank of Chile, 2012) are examples of using domestic currency as numeraire.

McCauley and Chan (2014), and Ito, McCauley, Chan (2015) provide evidence consistent with the use of domestic currency as numeraire. They estimate the currency movement for 25 economies, and find cross-sectional evidence that the share of the dollar in reserves is higher where the domestic currency varies less against the dollar than other major currencies. The relationship still holds after they exclude currencies with currency peg and currencies that the IMF characterizes as "crawl-like" or "other managed arrangement", which indicates the relationship does not depend on economies where the currency is heavily managed.

In order to quantify each country's currency co-movement with main reserve currencies, we adopt the method developed by Frankel and Wei (1994, and 2007).

$$
\Delta \ln \frac{X_{t}}{C H F_{t}}=\rho_{1} \Delta \ln \frac{E U R_{t}}{C H F_{t}}+\rho_{2} \Delta \ln \frac{J P Y_{t}}{C H F_{t}}+\rho_{3} \Delta \ln \frac{G B P_{t}}{C H F_{t}}+\rho_{4} \Delta \ln \frac{U S D_{t}}{C H F_{t}}+\alpha+\varepsilon_{t}
$$

$\frac{X_{t}}{C H F_{t}}$ is each country's exchange rate versus Swiss Franc. We name $\rho_{1}-\rho_{4}$ the weights of euro zone, yen zone, pound zone, and dollar zone.

Following McCauley and Chan (2014), we use a 10-year sample (2007 to September 2017) to estimate $\rho_{1}$ to $\rho_{4}$ for each country which releases its currency composition to COFER. ${ }^{12}$ The results are consistent with the use of domestic currency as numeraire (Figure 4).

\footnotetext{
${ }^{12}$ Euro zone countries (Belgium, Estonia, Finland, Germany, Ireland, Netherlands, and Portugal) are excluded in our analysis, as their $\rho_{1}=1$ by definition. Moldova and West Bank and Gaza are also excluded due to data limits.
}

CInternational Monetary Fund. Not for Redistribution 
Figure 4: The Share of EUR in FX vs Euro Zone Weight (left); and the Share of USD in FX vs Dollar Zone Weight (right) (2017 Q4)
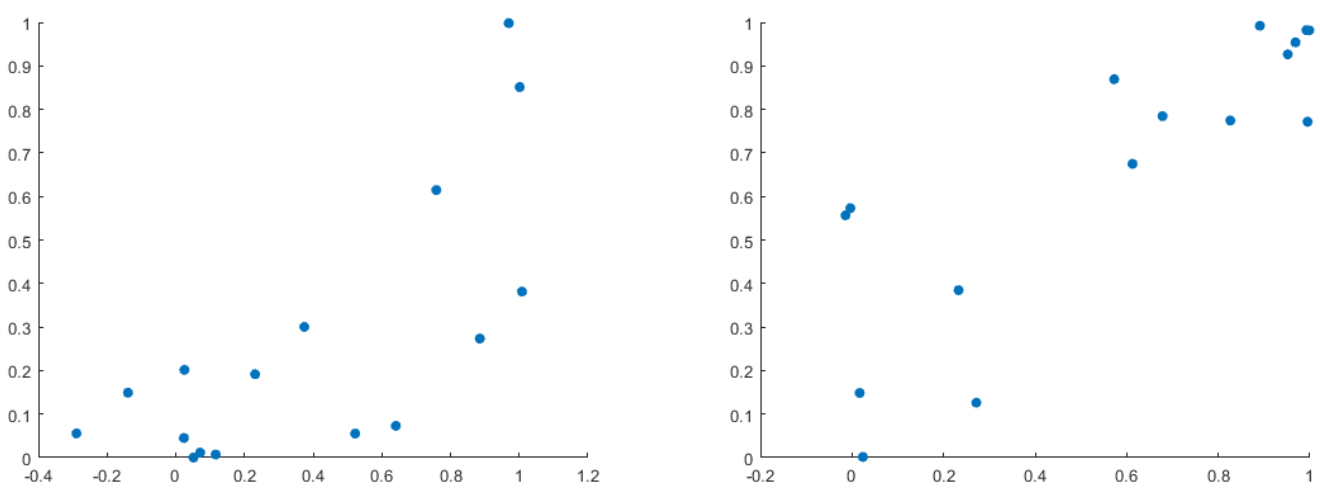

Sources: Bloomberg Finance L.P.; IMF COFER; and authors' calculations.

\subsection{Exchange rate risk and interest rate risk}

Our focus is on the exchange rate risk, as the exchange rate movement is much more volatile than the interest rate movement. It is consistent with the well-recognized stability of the government bond yield (Figures 5 and 6). For example, in the case of Australia, "The most significant of these risks is an exposure to fluctuations in the value of the Australian dollar against the currencies in which reserves are held" (Vallence, 2012). As shown later, our framework can be extended to incorporate the interest risk and other types of risks.

\subsection{Evidence from a reduced-form regression}

A reduced-form analysis is used to analyze the effect of the currency compositions of imports invoicing and short-term external debt, and risk and returns of exchange rates on the currency composition of FX reserves. The regression model can be presented as

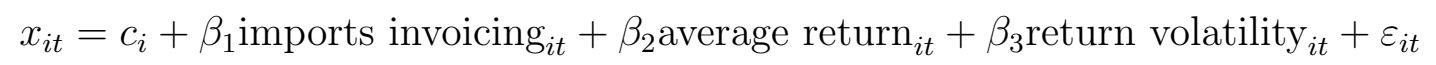

The fixed-effect estimators are the OLS estimators for

$x_{i t}-\bar{x}_{i}=\beta_{1}\left(\right.$ imports invoicing $\left._{i t}-\overline{\text { imports invoicing }_{i t}}\right)+\beta_{2}\left(\right.$ average return $\left._{i t}-\overline{{\text { average } \text { return }_{i}}}\right)$

$$
+\beta_{3}\left(\text { return volatility }_{i t}-\overline{\text { return volatility }_{i}}\right)+\left(\varepsilon_{i t}-\bar{\varepsilon}_{i}\right)
$$


Figure 5: Within-one-year Means of EUR, and USD Exchange Rate Returns and 2Y Government Bond Returns Averaged for Brazil, China, India, Russia, and Saudi Arabia (2006 Q1 - 2014 Q4)
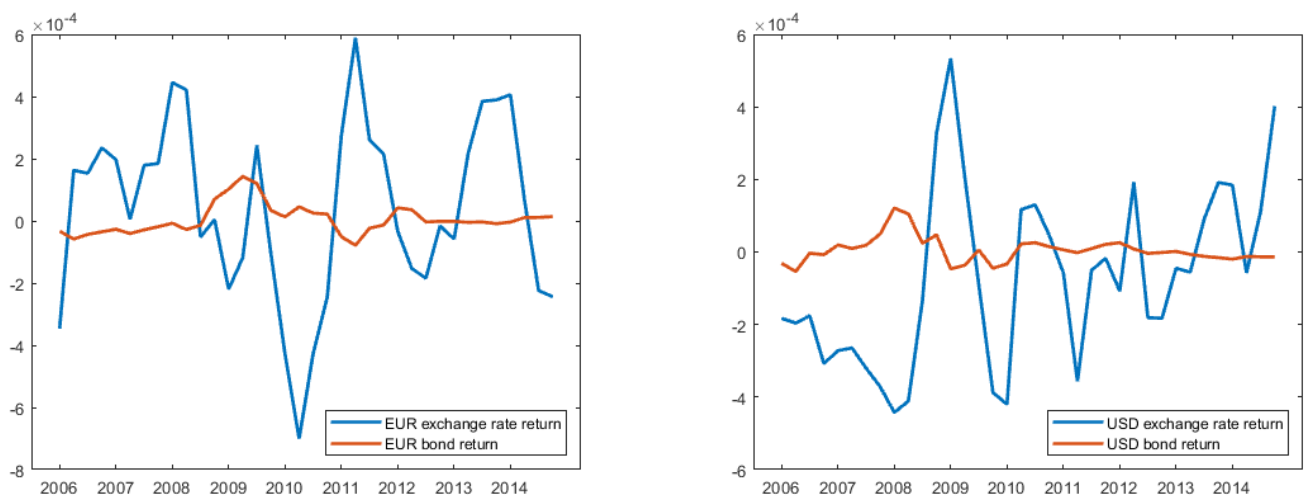

Sources: Bloomberg Finance L.P.; and authors' calculations.

Figure 6: Within-one-year Variance of Exchange Rate Returns (left) and 2 Y government Bond Returns (right) Averaged for Brazil, China, India, Russia, and Saudi Arabia (2006 Q1 - 2014 Q4)
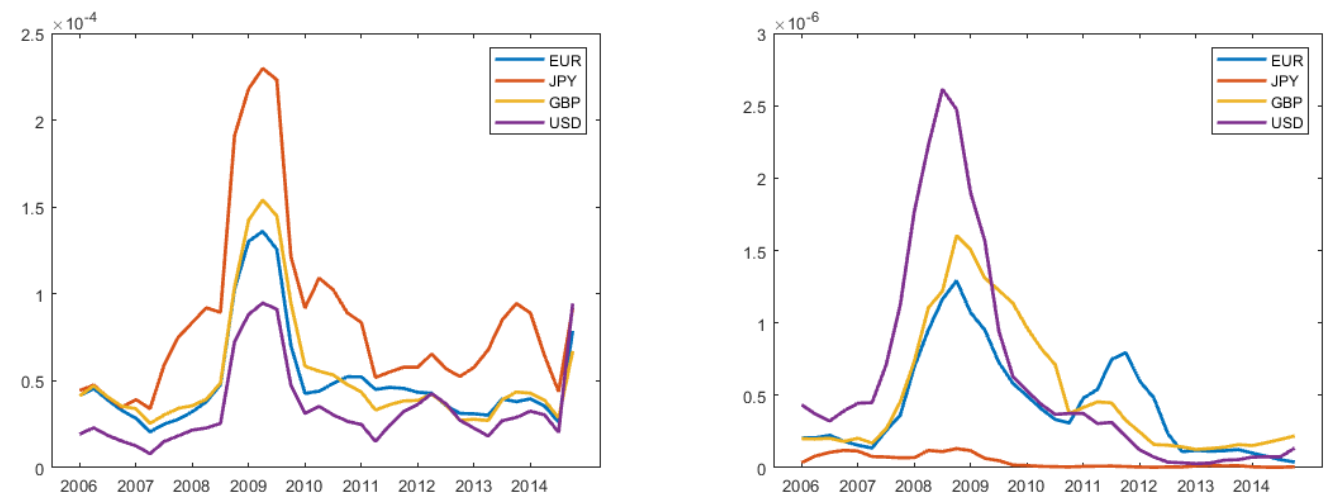

Sources: Bloomberg Finance L.P.; and authors' calculations.

where $x_{i t}$ is the share of reserve currency $i$ (either EUR, JPY, GBP, or USD) in period $t$ among our sample of emerging and developing countries' FX reserves; imports invoicing ${ }_{i t}$ is the share of currency $i$ among these countries' imports invoicing in period $t$; average $\operatorname{return}_{i t}$ is currency i's average return rates using SDR as numeraire in the past 7 years up to each 
quarter; and return volatility ${ }_{i t}$ is currency $i$ 's volatility of return rates using SDR as numeraire in the past 7 years up to each quarter. The results are presented in column (1) of Table 1.

In column (2), we use the share of reserve currency $i$ of these countries' short-term external debt. In column (3), we use the weighted average of the currency shares in imports invoicing and short-term external debt. The aggregate imports invoiced in the four reserve currencies is the weight for the former and the aggregate short-term external debt denominated in these currencies is the weight for the latter. In column (4), the 2-year government bond bid-ask spread is introduced as the control variable.

The results show that the currency compositions of imports invoicing and short-term external debt have significant effect on the currency composition of FX reserves; the return rates also have significant effect, consistent with the existence of the investment tranche; and the effect of the return volatility is not statistically significant, consistent with the results in Chan, Peng, and Shu (2011). The effect of the government bond spread is not statistically significant. We believe that, for these four main reserve currencies, the government bonds of their issuers are liquid enough so that their liquidity is not a major concern for reserve buyers. However, as discussed in Section 7.1, a liquid government bond market could be one necessary condition for central banks to hold these bonds.

\section{Data}

Our main sample includes 22 emerging and developing countries. ${ }^{13}$ The selection criteria is that they either had FX reserves exceeding USD10bn in 2017, or are included in the imports invoicing dataset in Gopinath (2016). As the aggregate FX reserves of these 22 countries accounted for 88 percent of the total FX reserve holdings of the emerging and developing economies in 2015 Q1, we use the currency composition of the emerging and developing countries' aggregate FX reserves reported by $\mathrm{COFER}^{14}$ to approximate

\footnotetext{
${ }^{13}$ They are Argentina, Brazil, Bulgaria, China, Columbia, Hungary, India, Indonesia, Jordan, Malaysia, Mexico, Morocco, Pakistan, Peru, Philippines, Poland, Romania, Russia, Saudi Arabia, Thailand, Turkey, and Ukraine.

${ }^{14}$ COFER data for individual countries are strictly confidential, except for several countries.
} 
Table 1. Results of the Reduced-form Regression

\begin{tabular}{|c|c|c|c|c|}
\hline & (1) & $(2)$ & (3) & (4) \\
\hline \multirow[t]{2}{*}{ imports invoicing } & $0.622^{* * *}$ & & & \\
\hline & $(4.90)$ & & & \\
\hline \multirow[t]{2}{*}{ ST external debt denomination } & & $0.413^{* * *}$ & & \\
\hline & & $(11.20)$ & & \\
\hline \multirow[t]{2}{*}{ imports invoicing and ST external debt denomination } & & & $0.549^{* * *}$ & $0.550^{* * *}$ \\
\hline & & & $(9.96)$ & $(9.98)$ \\
\hline \multirow[t]{2}{*}{ average return } & $47.60^{* *}$ & $97.10^{* * *}$ & $64.26^{* * *}$ & $69.51^{* * *}$ \\
\hline & $(2.15)$ & $(6.06)$ & $(3.76)$ & $(3.87)$ \\
\hline \multirow[t]{2}{*}{ return volatility } & -3.602 & 1.383 & -0.318 & -1.714 \\
\hline & $(-1.46)$ & $(0.69)$ & $(-0.15)$ & $(-0.67)$ \\
\hline \multirow[t]{2}{*}{ government bond spread } & & & & -9.588 \\
\hline & & & & $(-0.94)$ \\
\hline \multirow[t]{2}{*}{ const } & $0.117^{* * *}$ & $0.154^{* * *}$ & $0.115^{* * *}$ & $0.123^{* * *}$ \\
\hline & $(3.53)$ & (11.48) & $(6.35)$ & $(6.12)$ \\
\hline$N$ & 144 & 144 & 144 & 144 \\
\hline within R-square & 0.2459 & 0.5374 & 0.4859 & 0.4892 \\
\hline
\end{tabular}

$t$ statistics in parentheses.

${ }^{*} p<0.10,{ }^{* *} p<0.05,{ }^{* * *} p<0.01$

the currency composition of these 22 countries' aggregate FX reserves. The time period covered in our estimation is from 2006 Q1 to 2014 Q4, as the currency composition of emerging and developing countries' FX reserves became unavailable starting from 2015 Q1.

The data on the average currency composition of imports invoicing between 1999 and 2015 is from Gopinath (2016). We use that average to calculate the imports invoicing in 
each currency for each year due to data limits. ${ }^{15}$ For countries included in the dataset but with missing share for some reserve currency, and for those not included in the dataset, we approximate the currency composition of their imports invoicing as follows:

- If the country is included in the dataset but the share of some reserve currency is missing, we approximate the share using that currency's share in the imports invoicing of the countries with available data.

- If the country is not included in the dataset, we approximate each reserve currency's share using that currency's share in the imports invoicing of the countries with available data.

After the approximation, the sum of each country's imports invoiced in that reserve currency becomes the aggregate imports of all these 22 countries invoiced in that reserve currency.

Approximation is also applied for the currency composition of short-term external debt. The data on country-level short-term external debt is sourced from Haver. As there is almost no data on the currency composition of short-term external debt, we use the currency composition of total external debt or public and publicly-guaranteed (PPG) debt from World Bank International Debt Statistics as an approximation. In cases where PPG debt is unavailable for one country, we use the short-term external debt-weighted average of other countries' currency shares as the approximation for that country. Next we calculate each country's aggregate short-term external debt denominated in reserve currencies; and the aggregate short-term external debt of all these 22 countries denominated in each reserve currency.

To investigate the cross-sectional pattern, we use the rather limited quarterly countrylevel reserve currency composition data from the IMF COFER data. ${ }^{16}$ For each country, we calculate the currency share of EUR, JYP, GBP, and USD.

\footnotetext{
${ }^{15}$ The imports of goods data is from IMF DOTS; and the imports of service data is from UNCTAD.

${ }^{16}$ The data is available for Australia, Belgium, Brazil, Bulgaria, Chile, Costa Rica, Croatia, Estonia, Finland, Georgia, Germany, Ireland, Israel, Latvia, Mauritius, Moldova, Morocco, Netherlands, Norway, Peru, Portugal, Seychelles, Sweden, Switzerland, Ukraine, Uruguay, West Bank and Gaza.
} 


\section{$5 \quad$ A Portfolio Choice Model}

We have developed a portfolio choice model to analyze the currency allocation decision of central banks. In the model, the aggregate reserve portfolio of a central bank is divided into two tranches, liquidity tranche and investment tranche. The size of the FX obligations, denoted by $L$, is related to the value of FX used for the payment for imports and short-term external debt, using domestic currency as numeraire. There are other types of liabilities that could potentially call for FX, such as domestic deposits denominated in FX, M2, and other types of external liabilities (IMF, 2011). However, in this paper we only consider FX payment for imports and short-term external debt denominated in FX, as they are the most relevant FX-denominated potential drains for many countries. $y_{i}$ denotes the share of obligations in currency $i \in I . R_{i}$ denotes the growth rate of the value of currency $i$ obligations, which equals to the growth rate of the exchange rate of currency $i$ using domestic currency as numeraire. The value of the obligations one period later is

$$
\sum_{i} L y_{i}\left(1+R_{i}\right)=L\left(1+\sum_{i} y_{i} R_{i}\right)
$$

$A$ denotes the initial value of reserve assets (the aggregate portfolio). If $A>L$, the size of the liquidity tranche equals to $L$, the size of the investment tranche is $A-L$. If $A \leq L$, the whole portfolio is the liquidity tranche.

For simplicity, in our benchmark model, we assume the returns of the reserve assets using their denominate currency as numeraire are zero, therefore exchange rates are the only factor that affects the values of reserves assets. Under this assumption, as the assets denominated in the same reserve currency are essentially the same, the central banks' problem becomes a choice of currency allocation. This assumption is consistent with the observation of a much larger FX risk compared to interest rate risk (Figures 5 and 6). In reality, central banks we have seen do set the shares of reserve currencies as benchmark when managing their FX reserves. ${ }^{17}$ This assumption can be relaxed with details shown

\footnotetext{
${ }^{17}$ For example, Chile' central bank sets the reference structure of the medium-term liquidity portfolio to be USD 39\%, and EUR 36\% (Central Bank of Chile, 2012); for Sweden, its benchmark is USD 35\%, EUR 35\%, GBP $15 \%$ and JPY 15\%; for UK, its benchmark is USD 40\%, EUR 40\%, and JPY 20\%; for Hong Kong, the benchmark is USD 80\%, EUR 15\%, JPY 5\%; for Colombia, the benchmark is USD $80.4 \%$, EUR 15.3\%, JPY 4.2\%; and for Botswana, the currency composition of the short-term fund is
} 
in Appendix A.1.

The central bank chooses the currency share $x_{L i}, x_{I i}$ of each currency $i$ for the liquidity tranche and the investment tranche. The value of the liquidity tranche after one period is

$$
\sum_{i} L x_{L i}\left(1+R_{i}\right)=L\left(1+\sum_{i} x_{L i} R_{i}\right)
$$

The value of the investment tranche after one period is

$$
\sum_{i}(A-L) x_{I i}\left(1+R_{i}\right)=(A-L)\left(1+\sum_{i} x_{I i} R_{i}\right)
$$

The goal for the liquidity tranche is to maximize the surplus subject to some risk constraints $^{18}$

$$
L \sum_{i} x_{L i} R_{i}-L \sum_{i} y_{i} R_{i}
$$

It is equivalent to maximize $\frac{L \sum_{i} x_{L i} R_{i}-L \sum_{i} y_{i} R_{i}}{L}=\sum_{i}\left(x_{L i}-y_{i}\right) R_{i}$. The central bank's optimization problem for the liquidity tranche is

$$
\min _{\mathbf{x}_{L}} \frac{1}{2}\left(\mathbf{x}_{L}-\mathbf{y}\right)^{\top} \mathbf{\Omega}\left(\mathbf{x}_{L}-\mathbf{y}\right)-\lambda_{L} \mathbf{m}^{\top}\left(\mathbf{x}_{L}-\mathbf{y}\right)
$$

s.t. $\mathbf{e}^{\top} \mathbf{x}_{L}=1$

where $\Omega$ is the covariance matrix of the currency return rates, $\mathbf{m}$ is the expected return rates of currencies. The solution is

$$
\mathbf{x}_{L}=\mathbf{y}+\lambda_{L}\left(\boldsymbol{\Omega}^{-1} \mathbf{m}-\frac{\mathbf{e}^{\top} \Omega^{-1} \mathbf{m}}{\mathbf{e}^{\top} \Omega^{-1} \mathbf{e}} \mathbf{\Omega}^{-1} \mathbf{e}\right) .
$$

$\mathbf{y}$ is the minimum variance portfolio $\left(\lambda_{L}=0\right)$. If central banks do not have return concern for the liquidity tranche, the currency composition of the liquidity tranche will be set to be equal to the currency composition of the obligations.

The goal for the investment tranche is to maximize the returns subject to some risk constraints. It is equivalent to maximize $1+\sum_{i} x_{I i} R_{i}$. Thus the central bank's optimization problem for the investment tranche is

$$
\min _{\mathbf{x}_{I}} \frac{1}{2} \mathbf{x}_{I}^{\top} \mathbf{\Omega} \mathbf{x}_{I}-\lambda_{I} \mathbf{m}^{\top} \mathbf{x}_{I}
$$

USD 48.9\%, EUR 25.2\%, GBP 11.1\%, JPY 11.9\% (Boorman and Ingves, 2001).

${ }^{18}$ For example, for Colombia, its currency composition of the benchmark is determined by the expected denomination of the balance of payments outflows...in order to maintain the value of the reserves in terms of expected outflows (Boorman and Ingves, 2001).

(C) International Monetary Fund. Not for Redistribution 
s.t. $\mathbf{e}^{\top} \mathbf{x}_{I}=1$

The solution is

$$
\mathbf{x}_{I}=\frac{\Omega^{-1} \mathbf{e}}{\mathbf{e}^{\top} \Omega^{-1} \mathbf{e}}+\lambda_{I}\left(\Omega^{-1} \mathbf{m}-\frac{\mathbf{e}^{\top} \Omega^{-1} \mathbf{m}}{\mathbf{e}^{\top} \Omega^{-1} \mathbf{e}} \Omega^{-1} \mathbf{e}\right)
$$

If $A>L$, the currency composition of the whole reserve portfolio is

$$
\begin{gathered}
\mathbf{x}=\frac{L \mathbf{x}_{L}+(A-L) \mathbf{x}_{I}}{A}=\mathbf{x}_{I}+\frac{L}{A}\left(\mathbf{x}_{L}-\mathbf{x}_{I}\right) \\
=\frac{\Omega^{-1} \mathbf{e}}{\mathbf{e}^{\top} \Omega^{-1} \mathbf{e}}+\lambda_{I}\left(\Omega^{-1} \mathbf{m}-\frac{\mathbf{e}^{\top} \Omega^{-1} \mathbf{m}}{\mathbf{e}^{\top} \Omega^{-1} \mathbf{e}} \Omega^{-1} \mathbf{e}\right)+\frac{L}{A}\left(\mathbf{y}-\frac{\Omega^{-1} \mathbf{e}}{\mathbf{e}^{\top} \Omega^{-1} \mathbf{e}}+\left(\lambda_{L}-\lambda_{I}\right)\left(\Omega^{-1} \mathbf{m}-\frac{\mathbf{e}^{\top} \Omega^{-1} \mathbf{m}}{\mathbf{e}^{\top} \boldsymbol{\Omega}^{-1} \mathbf{e}} \Omega^{-1} \mathbf{e}\right)\right)
\end{gathered}
$$

If $A \leq L$, the whole portfolio is the liquidity tranche; we assume the central banks only take the maximal size of obligation that can be covered by the reserves, that is $A$, into consideration, which implies $\mathbf{x}=\mathbf{x}_{L} \cdot{ }^{19}$

In the optimization problems shown above, we assume central banks use their domestic currencies as the numeraire when valuing the investment tranche and the surplus of the liquidity tranche. The choice of numeraire matters for the optimal currency allocation, as the returns and risk of reserve currencies are affected by which currency is chosen as the unit of account. Based on the empirical evidence and case studies, using domestic currency as the numeraire is a reasonable assumption to make. However it does not preclude that some countries might use USD or SDR or a basket of currencies as the numeraire. If the return is not the concern for the liquidity tranche $\left(\lambda_{L}=0\right)$, the currency composition of the liquidity tranche is determined by the currency composition of the obligations; and therefore only the currency composition of the investment tranche is affected by the choice of numeraire.

The FX obligations depend on the imports payment and short-term external debt service,

$$
L \mathbf{y}=a \mathbf{T}+b \mathbf{D}
$$

where $\mathbf{T}$ are the imports invoicing in foreign currencies, $\mathbf{D}$ are the short-term external debt denominated in foreign currencies. As the foreign currencies in imports invoicing

\footnotetext{
${ }^{19}$ Thus this assumption leads to the result that if the return is not the concern for their liquidity tranche, then for the central banks with inadequate reserves, the currency composition of their reserve portfolio is in accordance with the that of obligations. This result is consistent with many central banks' practices.
} 
and external debt denomination are dominated by EUR, JPY, GBP, and USD ${ }^{20}$ we only need to look at the import invoicing and short-term external debt denominated in these four main reserve currencies. Our model and estimation can be extended to incorporate more currencies in imports invoicing and short-term external debt denomination.

The aggregate obligation and the size of the liquidity tranche are

$$
\begin{gathered}
L=\mathbf{e}^{\top} L \mathbf{y}=\mathbf{e}^{\top}(a \mathbf{T}+b \mathbf{D}) \\
\mathbf{y}=\frac{a \mathbf{T}+b \mathbf{D}}{\mathbf{e}^{\top}(a \mathbf{T}+b \mathbf{D})}
\end{gathered}
$$

In some period, for the central bank with $L<A$, there is investment tranche. These central banks are denoted by $l \in J_{1}$; for the central bank with $L \geq A$, there is no investment tranche. These central banks are denoted by $l \in J_{2}$.

$$
l \in\left\{\begin{array}{l}
J_{1} \text { if } \mathbf{e}^{\top}\left(a \mathbf{T}_{l}+b \mathbf{D}_{l}\right)<A_{l} \\
J_{2} \text { if } \mathbf{e}^{\top}\left(a \mathbf{T}_{l}+b \mathbf{D}_{l}\right) \geq A_{l}
\end{array}\right.
$$

The optimal currency composition of each of central bank $l \in J_{1}$ are

$$
\begin{gathered}
\mathbf{x}=\frac{\Omega^{-1} \mathbf{e}}{\mathbf{e}^{\top} \boldsymbol{\Omega}^{-1} \mathbf{e}}+\lambda_{I}\left(\boldsymbol{\Omega}^{-1} \mathbf{m}-\frac{\mathbf{e}^{\top} \boldsymbol{\Omega}^{-1} \mathbf{m}}{\mathbf{e}^{\top} \boldsymbol{\Omega}^{-1} \mathbf{e}} \boldsymbol{\Omega}^{-1} \mathbf{e}\right)+\frac{1}{A}\left(a\left(\mathbf{T}-\frac{\boldsymbol{\Omega}^{-1} \mathbf{e}}{\mathbf{e}^{\top} \boldsymbol{\Omega}^{-1} \mathbf{e}} \mathbf{e}^{\top} \mathbf{T}\right)+b\left(\mathbf{D}-\frac{\boldsymbol{\Omega}^{-1} \mathbf{e}}{\mathbf{e}^{\top} \boldsymbol{\Omega}^{-1} \mathbf{e}} \mathbf{e}^{\top} \mathbf{D}\right)\right) \\
+\frac{1}{A}\left(\lambda_{L}-\lambda_{I}\right)\left(\boldsymbol{\Omega}^{-1} \mathbf{m}-\frac{\mathbf{e}^{\top} \boldsymbol{\Omega}^{-1} \mathbf{m}}{\mathbf{e}^{\top} \boldsymbol{\Omega}^{-1} \mathbf{e}} \boldsymbol{\Omega}^{-1} \mathbf{e}\right) \mathbf{e}^{\top}(a \mathbf{T}+b \mathbf{D})
\end{gathered}
$$

The optimal currency composition of central bank $l \in J_{2}$ are,

$$
\mathbf{x}=\frac{a \mathbf{T}+b \mathbf{D}}{\mathbf{e}^{\top}(a \mathbf{T}+b \mathbf{D})}+\lambda_{L}\left(\boldsymbol{\Omega}^{-1} \mathbf{m}-\frac{\mathbf{e}^{\top} \boldsymbol{\Omega}^{-1} \mathbf{m}}{\mathbf{e}^{\top} \boldsymbol{\Omega}^{-1} \mathbf{e}} \boldsymbol{\Omega}^{-1} \mathbf{e}\right)
$$

By using the data of reserve size, we can derive the optimal currency composition of FX reserves of all central banks $l \in J_{1}$ and $l \in J_{2}$, assuming each central bank has the same $\lambda_{L}, \lambda_{I}, a, b,{ }^{21}$

$$
\mathbf{x}_{\text {aggregate }}\left(\mathbf{A}, \boldsymbol{\Omega}, \mathbf{m}, \mathbf{T}, \mathbf{D}, a, b, \lambda_{I}, \lambda_{L}\right):=\frac{\sum_{l \in J} A_{l} \mathbf{x}_{l}}{\sum_{l \in J} A_{l}}=\frac{\sum_{l \in J_{1}} A_{l} \frac{\boldsymbol{\Omega}_{l}^{-1} \mathbf{e}}{\mathbf{e}^{\top} \boldsymbol{\Omega}_{l}^{-1} \mathbf{e}}}{\sum_{l \in J} A_{l}}
$$

\footnotetext{
${ }^{20}$ Based on the dataset from Gopinath (2016), almost all the imports are invoiced in EUR, JPY, GBP, USD. In our sample, the share of external debt denominated in EUR, JPY, GBP, USD is nearly $90 \%$. The ratio would be even higher if the external debt denominated in the domestic currency is excluded.

${ }^{21}$ The assumption of homogeneous $\lambda_{I}, \lambda_{L}, a, b$ among central banks can be relaxed. Due to a relatively small sample of observations, this assumption is made to reduce the number of parameters we need to estimate.
} 


$$
\begin{aligned}
& +a \frac{\sum_{l \in J_{1}}\left(\mathbf{T}_{l}-\frac{\boldsymbol{\Omega}_{l}^{-1} \mathbf{e}}{\mathbf{e}^{\top} \boldsymbol{\Omega}_{l}^{-1} \mathbf{e}} \mathbf{e}^{\top} \mathbf{T}_{l}\right)}{\sum_{l \in J} A_{l}}+b \frac{\sum_{l \in J_{1}}\left(\mathbf{D}_{l}-\frac{\boldsymbol{\Omega}_{l}^{-1} \mathbf{e}}{\mathbf{e}^{\top} \boldsymbol{\Omega}_{l}^{-1} \mathbf{e}} \mathbf{e}^{\top} \mathbf{D}_{l}\right)}{\sum_{l \in J} A_{l}}+\frac{\sum_{l \in J_{2}} A_{l} \frac{a \mathbf{T}_{l}+b \mathbf{D}_{l}}{\mathbf{e}^{\top}\left(a \mathbf{T}_{l}+b \mathbf{D}_{l}\right)}}{\sum_{l \in J} A_{l}} \\
& +\lambda_{I}\left(\frac{\sum_{l \in J_{1}} A_{l}\left(\boldsymbol{\Omega}_{l}^{-1} \mathbf{m}_{l}-\frac{\mathbf{e}^{\boldsymbol{\top}} \boldsymbol{\Omega}_{l}^{-1} \mathbf{m}_{l}}{\mathbf{e}^{\top} \boldsymbol{\Omega}_{l}^{-1} \mathbf{e}} \boldsymbol{\Omega}_{l}^{-1} \mathbf{e}\right)}{\sum_{l \in J} A_{l}}-\frac{\sum_{l \in J_{1}}\left(\boldsymbol{\Omega}_{l}^{-1} \mathbf{m}_{l}-\frac{\mathrm{e}^{\boldsymbol{\top}} \boldsymbol{\Omega}_{l}^{-1} \mathbf{m}_{l}}{\mathbf{e}^{\boldsymbol{\top}} \boldsymbol{\Omega}_{l}^{-1} \mathbf{e}} \boldsymbol{\Omega}_{l}^{-1} \mathbf{e}\right) \mathbf{e}^{\boldsymbol{\top}}\left(a \mathbf{T}_{l}+b \mathbf{D}_{l}\right)}{\sum_{l \in J} A_{l}}\right) \\
& +\lambda_{L}\left(\frac{\sum_{l \in J_{1}}\left(\boldsymbol{\Omega}_{l}^{-1} \mathbf{m}_{l}-\frac{\mathbf{e}^{\top} \boldsymbol{\Omega}_{l}^{-1} \mathbf{m}_{l}}{\mathbf{e}^{\top} \boldsymbol{\Omega}_{l}^{-1} \mathbf{e}} \boldsymbol{\Omega}_{l}^{-1} \mathbf{e}\right) \mathbf{e}^{\boldsymbol{\top}}\left(a \mathbf{T}_{l}+b \mathbf{D}_{l}\right)}{\sum_{l \in J} A_{l}}+\frac{\sum_{l \in J_{2}} A_{l}\left(\boldsymbol{\Omega}_{l}^{-1} \mathbf{m}_{l}-\frac{\mathbf{e}^{\top} \boldsymbol{\Omega}_{l}^{-1} \mathbf{m}_{l}}{\mathbf{e}^{\top} \boldsymbol{\Omega}_{l}^{-1} \mathbf{e}} \boldsymbol{\Omega}_{l}^{-1} \mathbf{e}\right)}{\sum_{l \in J} A_{l}}\right),
\end{aligned}
$$

\section{Estimation}

\subsection{Results}

For each quarter $t$ and central bank $l$, the covariance matrix $\Omega_{l t}$ and mean vector $\mathbf{m}_{l t}$ of the reserve currencies can be estimated using the latest seven-year sample up to quarter $t$. For each central bank $l$, the choice of the numeraire affects $\Omega_{l t}$ and $\mathbf{m}_{l t}$ of the reserve currencies. In our estimation we assume each central bank uses its domestic currency as the numeraire. This assumption can be relaxed if more information about central banks' numeraire choices are available.

Define $\boldsymbol{\Lambda}_{t}:=\left(\mathbf{A}_{t}, \boldsymbol{\Omega}_{t}, \mathbf{m}_{t}, \mathbf{T}_{t}, \mathbf{D}_{t}\right)$ and $\mathbf{u}_{i}\left(\boldsymbol{\Lambda}_{t}, a, b\right)$ as a $9 \times 1$ vector,

$$
\begin{aligned}
& \mathbf{u}_{i 1}=\frac{\sum_{l \in J_{1}} A_{l t} \frac{\left(\boldsymbol{\Omega}_{l t}^{-1} \mathbf{e}\right)_{i}}{\mathbf{e}^{\top} \boldsymbol{\Omega}_{l t}^{-1} \mathbf{e}}}{\sum_{l \in J} A_{l t}}, \mathbf{u}_{i 2}=\frac{\sum_{l \in J_{1}}\left(\mathbf{T}_{l t}-\frac{\boldsymbol{\Omega}_{l t}^{-1} \mathbf{e}}{\mathbf{e}^{\top} \boldsymbol{\Omega}_{l t}^{-1} \mathbf{e}} \mathbf{e}^{\top} \mathbf{T}_{l t}\right)_{i}}{\sum_{l \in J} A_{l t}}, \mathbf{u}_{i 3}=\frac{\sum_{l \in J_{1}}\left(\mathbf{D}_{l t}-\frac{\boldsymbol{\Omega}_{l t}^{-1} \mathbf{e}}{\mathbf{e}^{\top} \boldsymbol{\Omega}_{l t}^{-1} \mathbf{e}} \mathbf{e}^{\top} \mathbf{D}_{l t}\right)_{i}}{\sum_{l \in J} A_{l t}} \\
& \mathbf{u}_{i 4}=\frac{\sum_{l \in J_{2}} A_{l t} \frac{\left(\mathbf{T}_{l t}\right)_{i}}{\mathbf{e}^{\boldsymbol{\top}}\left(a \mathbf{T}_{l t}+b \mathbf{D}_{l t}\right)}}{\sum_{l \in J} A_{l t}}, \mathbf{u}_{i 5}=\frac{\sum_{l \in J_{2}} A_{l t} \frac{\left(\mathbf{D}_{l t}\right)_{i}}{\mathbf{e}^{\top}\left(a \mathbf{T}_{l t}+b \mathbf{D}_{l t}\right)}}{\sum_{l \in J} A_{l t}}, \mathbf{u}_{i 6}=\frac{\sum_{l \in J_{1}} A_{l t}\left(\boldsymbol{\Omega}_{l t}^{-1} \mathbf{m}_{l t}-\frac{\mathbf{e}^{\boldsymbol{\top}} \boldsymbol{\Omega}_{l t}^{-1} \mathbf{m}_{l t}}{\mathbf{e}^{\top} \boldsymbol{\Omega}_{l t}^{-1} \mathbf{e}} \boldsymbol{\Omega}_{l t}^{-1} \mathbf{e}\right)_{i}}{\sum_{l \in J} A_{l t}} \\
& \mathbf{u}_{i 7}=\frac{\sum_{l \in J_{1}}\left(\boldsymbol{\Omega}_{l t}^{-1} \mathbf{m}_{l t}-\frac{\mathbf{e}^{\top} \boldsymbol{\Omega}_{l t}^{-1} \mathbf{m}_{l t}}{\mathbf{e}^{\top} \boldsymbol{\Omega}_{l t}^{-1} \mathbf{e}} \boldsymbol{\Omega}_{l t}^{-1} \mathbf{e}\right)_{i} \mathbf{e}^{\top} \mathbf{T}_{l t}}{\sum_{l \in J} A_{l t}}, \mathbf{u}_{i 8}=\frac{\sum_{l \in J_{1}}\left(\boldsymbol{\Omega}_{l t}^{-1} \mathbf{m}_{l t}-\frac{\mathbf{e}^{\top} \boldsymbol{\Omega}_{l t}^{-1} \mathbf{m}_{l t}}{\mathbf{e}^{\top} \boldsymbol{\Omega}_{l t}^{-1} \mathbf{e}} \boldsymbol{\Omega}_{l t}^{-1} \mathbf{e}\right)_{i} \mathbf{e}^{\top} \mathbf{D}_{l t}}{\sum_{l \in J} A_{l t}} \\
& \mathbf{u}_{i 9}=\frac{\sum_{l \in J_{2}} A_{l t}\left(\boldsymbol{\Omega}_{l t}^{-1} \mathbf{m}_{l t}-\frac{\mathbf{e}^{\boldsymbol{\top}} \boldsymbol{\Omega}_{l t}^{-1} \mathbf{m}_{l t}}{\mathbf{e}^{\boldsymbol{\top}} \boldsymbol{\Omega}_{l t}^{-1} \mathbf{e}} \boldsymbol{\Omega}_{l t}^{-1} \mathbf{e}\right)_{i}}{\sum_{l \in J} A_{l t}}
\end{aligned}
$$

We have

$$
\mathbf{x}\left(\boldsymbol{\Lambda}_{t}, a, b, \lambda_{I}, \lambda_{L}\right)_{\text {aggregate }, i}=\left(1, a, b, a, b, \lambda_{I},\left(\lambda_{L}-\lambda_{I}\right) a,\left(\lambda_{L}-\lambda_{I}\right) b, \lambda_{L}\right) \mathbf{u}_{i}\left(\boldsymbol{\Lambda}_{t}, a, b\right)
$$


Assuming $x_{i t}$, the share of currency $i$ in countries' FX reserves in quarter $t$, satisfies

$$
x_{i t}=c_{i}+\beta \mathbf{x}\left(\boldsymbol{\Lambda}_{t}, a, b, \lambda_{I}, \lambda_{L}\right)_{\text {aggregate }, i}+\varepsilon_{i t},
$$

where $c_{i}$ is the currency-specific fixed term, capturing the time-invariant currency-specific factor in a reduced-form way. We expect $c_{i}$ of euro and dollar to be much higher than that of yen and pound, reflecting the privilege of euro and dollar. ${ }^{22} \varepsilon_{i t}$ captures the unobserved shocks and the measurement errors. The solution to our portfolio choice model in Section 5 delivers how the time-varying component of the currency composition of FX reserves, $\beta \mathbf{x}\left(\boldsymbol{\Lambda}_{t}, a, b, \lambda_{I}, \lambda_{L}\right)_{\text {aggregate }, i}$, depends on the observed variables and the model's parameters. $\beta$ is expected to be smaller than one, as it captures the fact that central banks are reluctant to rapidly adjust the currency composition of their FX reserves. There are several plausible reasons for that reluctance. First, there is a strong inertia bias in favor of using currency that has been the international currency in the past (Chinn and Frankel, 2005); and second, central banks prefer to see a stable composition for the reserves that would help to explain a consistent investment policy (Ramaswamy, 1999). ${ }^{23}$

Then

$$
\begin{gathered}
x_{i t}-\bar{x}_{i}=\beta\left(\mathbf{x}\left(\boldsymbol{\Lambda}_{t}, a, b, \lambda_{I}, \lambda_{L}\right)_{\text {aggregate }, i}-\overline{\mathbf{x}}\left(\boldsymbol{\Lambda}_{t}, a, b, \lambda_{I}, \lambda_{L}\right)_{\text {aggregate }, i}\right)+\varepsilon_{i t}-\bar{\varepsilon}_{i} \\
=\beta\left(1, a, b, a, b, \lambda_{I},\left(\lambda_{L}-\lambda_{I}\right) a,\left(\lambda_{L}-\lambda_{I}\right) b, \lambda_{L}\right)\left(\mathbf{u}_{i}\left(\boldsymbol{\Lambda}_{t}, a, b\right)-\overline{\mathbf{u}}_{i}\left(\boldsymbol{\Lambda}_{t}, a, b\right)\right)+\varepsilon_{i t}-\bar{\varepsilon}_{i},
\end{gathered}
$$

A GMM estimator is adopted. We use the orthogonality conditions as the moment conditions,

$$
\begin{gathered}
E\left[\left(\mathbf{u}_{i t}\left(a_{0}, b_{0}\right)-\overline{\mathbf{u}}_{i}\left(a_{0}, b_{0}\right)\right)\left(\varepsilon_{i t}-\bar{\varepsilon}_{i}\right)\right]=0 \\
E\left[\varepsilon_{i t}-\bar{\varepsilon}_{i}\right]=0
\end{gathered}
$$

which are expressed as

$$
E\left[\mathbf{h}_{i}\left(\mathbf{x}_{t}, \boldsymbol{\Lambda}_{t}, a_{0}, b_{0}, \beta_{0}, \lambda_{I 0}, \lambda_{L 0}\right)\right]=0
$$

\footnotetext{
${ }^{22}$ The magnitude of this term may be determined by the reserve currency issuer's relatively stable and persistent characteristics, for example, the economy's size, the size of the financial markets, and the economy's status in the world.

${ }^{23}$ In our baseline estimation, we implicitly assume $\beta$ are the same for central banks' liquidity tranche and investment tranche. This assumption can be relaxed.
} 
where

$$
\begin{gathered}
\mathbf{h}_{i}\left(\mathbf{x}_{t}, \boldsymbol{\Lambda}_{t}, a, b, \beta, \lambda_{I}, \lambda_{L}\right)=\left(\mathbf{u}_{i}\left(\boldsymbol{\Lambda}_{t}, a, b\right)-\overline{\mathbf{u}}_{i}\left(\boldsymbol{\Lambda}_{t}, a, b\right), 1\right) \\
\left(x_{i t}-\bar{x}_{i}-\beta\left(1, a, b, a, b, \lambda_{I},\left(\lambda_{L}-\lambda_{I}\right) a,\left(\lambda_{L}-\lambda_{I}\right) b, \lambda_{L}\right)\left(\mathbf{u}_{i}\left(\boldsymbol{\Lambda}_{t}, a, b\right)-\overline{\mathbf{u}}_{i}\left(\boldsymbol{\Lambda}_{t}, a, b\right)\right)\right)
\end{gathered}
$$

We define $\theta=\left(a, b, \beta, \lambda_{I}, \lambda_{L}\right)$, and assume the identification condition holds, i.e., $\theta_{0}$ is the only solution to $E\left[\mathbf{h}_{i}\left(\mathbf{x}_{t}, \boldsymbol{\Lambda}_{t}, \theta_{0}\right)\right]=0$.

A two-step estimation approach is adopted.

\section{Step 1:}

We find $\theta^{*}=\left(a^{*}, b^{*}, \beta^{*}, \lambda_{I}^{*}, \lambda_{L}^{*}\right)$ that minimizes

$$
\left(\frac{1}{n} \sum_{i t} \mathbf{h}_{i}\left(\mathbf{x}_{t}, \boldsymbol{\Lambda}_{t}, a, b, \beta, \lambda_{I}, \lambda_{L}\right)^{\top}\right) \mathbf{I}_{n}\left(\frac{1}{n} \sum_{i t} \mathbf{h}_{i}\left(\mathbf{x}_{t}, \boldsymbol{\Lambda}_{t}, a, b, \beta, \lambda_{I}, \lambda_{L}\right)\right)
$$

where $\mathbf{I}_{n}$ is the identity matrix.

We can implement this minimization in two steps.

$$
x_{i t}-\bar{x}_{i}=\beta\left(1, \lambda_{I}, \lambda_{L}\right)\left(\left(\begin{array}{c}
\mathbf{u}_{i 1}+a\left(\mathbf{u}_{i 2}+\mathbf{u}_{i 4}\right)+b\left(\mathbf{u}_{i 3}+\mathbf{u}_{i 5}\right) \\
\mathbf{u}_{i 6}-a \mathbf{u}_{i 7}-b \mathbf{u}_{i 8} \\
a \mathbf{u}_{i 7}+b \mathbf{u}_{i 8}+\mathbf{u}_{i 9} \\
+\varepsilon_{i t}-\bar{\varepsilon}_{i}
\end{array}\right)-\left(\begin{array}{c}
\overline{\mathbf{u}}_{i 1}+a\left(\overline{\mathbf{u}}_{i 2}+\overline{\mathbf{u}}_{i 4}\right)+b\left(\overline{\mathbf{u}}_{i 3}+\overline{\mathbf{u}}_{i 5}\right) \\
\overline{\mathbf{u}}_{i 6}-a \overline{\mathbf{u}}_{i 7}-b \overline{\mathbf{u}}_{i 8} \\
a \overline{\mathbf{u}}_{i 7}+b \overline{\mathbf{u}}_{i 8}+\overline{\mathbf{u}}_{i 9}
\end{array}\right)\right)
$$

The closed-form expression of $(a, b), \beta^{*}(a, b), \lambda_{I}^{*}(a, b), \lambda_{L}^{*}(a, b)$ makes the overall minimization task much more computationally feasible. The objective function above is minimized by searching for $\left(a^{*}, b^{*}\right)$.

\section{Step 2:}

$\mathbf{W}_{n}$ is defined by

$$
\mathbf{W}_{n}:=\left(\frac{1}{n} \sum_{i t} \mathbf{h}_{i}\left(\mathbf{x}_{t}, \boldsymbol{\Lambda}_{t}, a^{*}, b^{*}, \beta^{*}, \lambda_{I}^{*}, \lambda_{L}^{*}\right) \mathbf{h}_{i}\left(\mathbf{x}_{t}, \boldsymbol{\Lambda}_{t}, a^{*}, b^{*}, \beta^{*}, \lambda_{I}^{*}, \lambda_{L}^{*}\right)^{\top}\right)^{-1}
$$

we find $\hat{\theta}=\left(\hat{a}, \hat{b}, \hat{\beta}, \hat{\lambda}_{I}, \hat{\lambda}_{L}\right)$ that minimizes

$$
\left(\frac{1}{n} \sum_{i t} \mathbf{h}_{i}\left(\mathbf{x}_{t}, \boldsymbol{\Lambda}_{t}, a, b, \lambda_{I}, \lambda_{L}\right)^{\top}\right) \mathbf{W}_{n}\left(\frac{1}{n} \sum_{i t} \mathbf{h}_{i}\left(\mathbf{x}_{t}, \boldsymbol{\Lambda}_{t}, a, b, \lambda_{I}, \lambda_{L}\right)\right)
$$

via the same two steps as shown in step 1 , using $\mathbf{W}_{n}$ as the weight matrix. 
The estimation results are presented in Table 2. More details about the estimation are shown in the Appendix A.2. We can not reject the null hypothesis that $\lambda_{L}=0$, which is consistent with the fact that returns are not the objective of the liquidity tranche.

Table 2. Estimation Results

\begin{tabular}{ccccc}
\hline \hline$a$ & $b$ & $\beta$ & $\lambda_{I}$ & $\lambda_{L}$ \\
\hline $2.6101^{* * *}$ & $2.3853^{* * *}$ & $0.5086^{* * *}$ & $0.0419^{* * *}$ & -0.0017 \\
$(3.1603)$ & $(2.7436)$ & $(7.0743)$ & $(5.9580)$ & $(-0.5094)$ \\
\hline \hline
\end{tabular}

$t$ statistics in parentheses.

${ }^{*} p<0.10,{ }^{* *} p<0.05,{ }^{* * *} p<0.01$

Figure 7 shows the actual and fitted euro and dollar shares in the 22 emerging and developing countries' FX reserves. ${ }^{24}$ We can see that the fitted shares can capture well the trend and fluctuations of the actual shares.

Using the estimates, we can estimate the size of the liquidity tranche and investment tranche at the country and aggregate levels.

$$
\begin{aligned}
& L_{\text {aggregate liquidity }}=\sum_{l \in J_{1}} \mathbf{e}^{\top}(a \mathbf{T}+b \mathbf{D})+\sum_{l \in J_{2}} A_{l} \\
& L_{\text {aggregate investment }}=\sum_{l \in J_{1}}\left(A_{l}-\mathbf{e}^{\top}(a \mathbf{T}+b \mathbf{D})\right)
\end{aligned}
$$

Compared to 2006 and 2007, there has been a significant increase in the absolute and relative sizes of the aggregate investment tranche afterwards (Figure 8). After 2008, despite the growth of the aggregate reserve portfolio, the absolute size of the developing countries' aggregate investment tranche has been stable, and the absolute and relative sizes of the liquidity tranche has been growing, driven by the growing imports invoicing

${ }^{24} c_{i}$ is estimated by assuming the moment condition $E_{t}\left(c_{i} \varepsilon_{i t}\right)=0$ in equation (2), so $\hat{c}_{i}$ is calculated from

$$
\frac{1}{T} \sum_{t} x_{i t}=\hat{c}_{i}+\beta \frac{1}{T} \sum_{t} \mathbf{x}\left(\boldsymbol{\Lambda}_{t}, \hat{a}, \hat{b}, \hat{\lambda}_{I}, \hat{\lambda}_{L}\right)_{\text {aggregate }, i}
$$

The estimates are $c_{E U R}=0.1814, c_{J P Y}=0.0070, c_{G B P}=0.0590, c_{U S D}=0.2439$. That indicates dollar and euro enjoy great privilege compared with yen and pound. Note the difference between $c_{E U R}$ and $c_{U S D}(0.0625)$ is much smaller than the difference between euro's and dollar's share in the FX reserves we see in the data (between 0.3 and 0.5 ), indicating our model is able to explain most of the difference between euro's and dollar's share in the FX reserves.

(C) International Monetary Fund. Not for Redistribution 
Figure 7: Actual and Fitted Shares of EUR (left) and of USD (right) (2006 Q1-2014Q4)
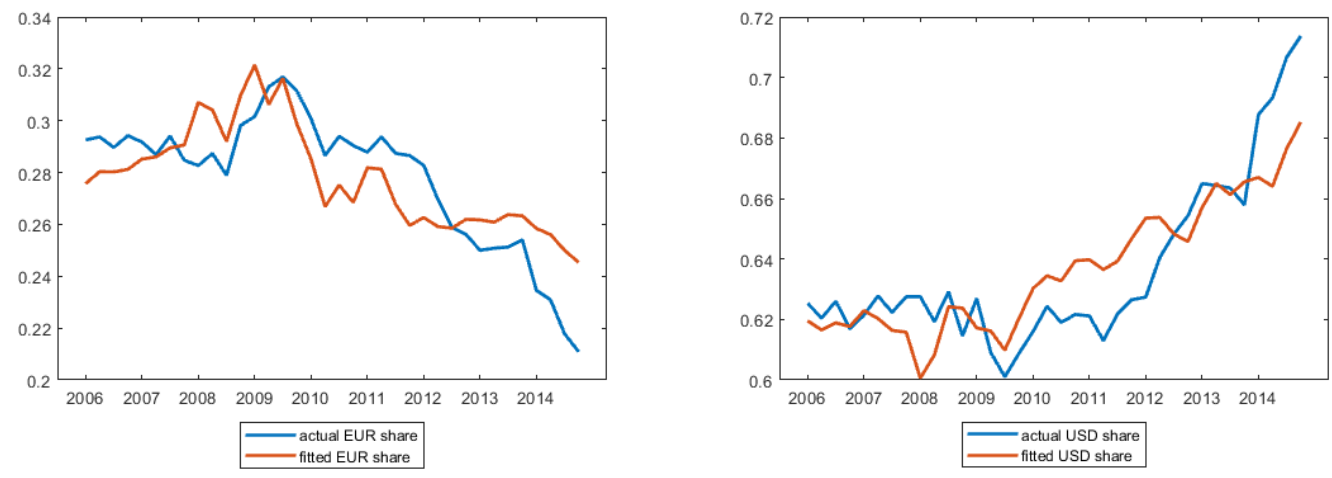

Sources: IMF COFER; and authors' calculations.

and short-term external debt denominated in reserve currencies.

Figure 8: FX Reserves and the Estimated Size of the Liquidity Tranche (2006 Q1 - 2014 Q4)

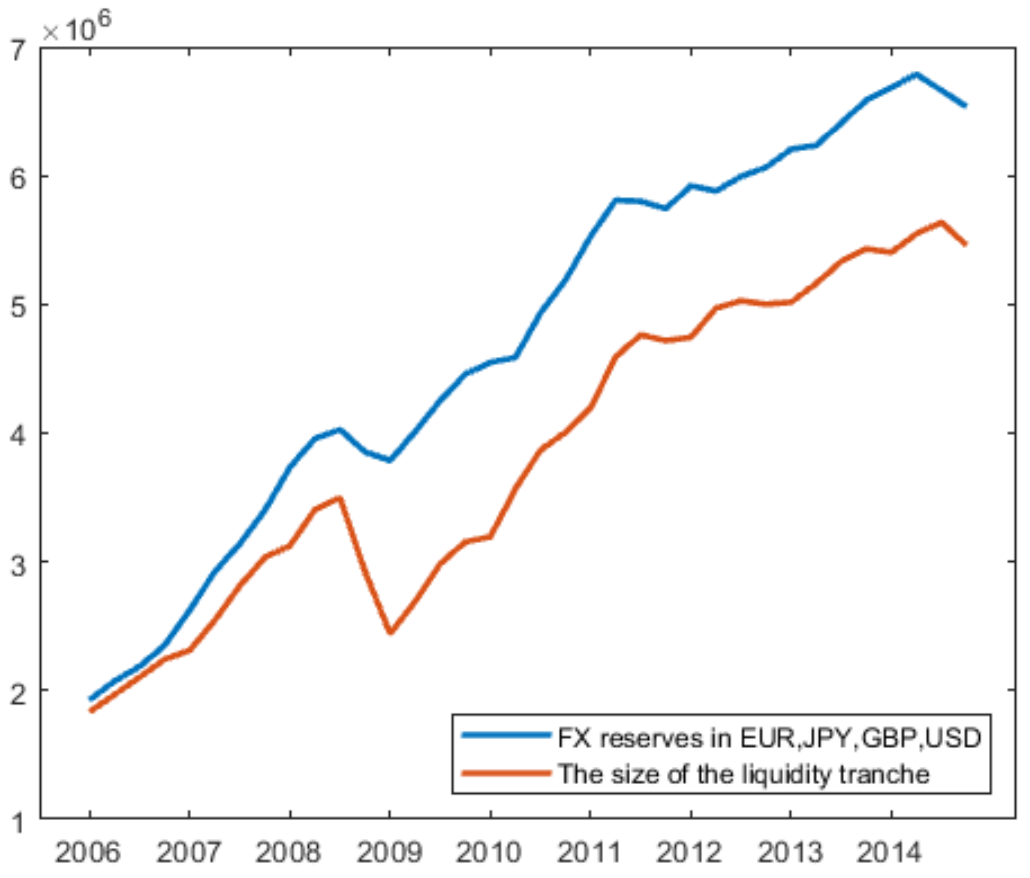

Sources: Federal Reserve Bank of St. Louis; Haver; IMF COFER; and authors' calculations. 
With the estimates, we can estimate the optimal currency composition of the aggregate liquidity tranche and investment tranche.

$$
\begin{gathered}
\mathbf{x}_{\text {aggregate liquidity }}=\frac{\sum_{l \in J_{1}}\left(a \mathbf{T}_{l}+b \mathbf{D}_{l}\right)+\sum_{l \in J_{2}} A_{l} \frac{a \mathbf{T}_{l}+b \mathbf{D}_{l}}{\mathbf{e}^{\top}\left(a \mathbf{T}_{l}+b \mathbf{D}_{l}\right)}}{\sum_{l \in J_{1}} \mathbf{e}^{\top}(a \mathbf{T}+b \mathbf{D})+\sum_{l \in J_{2}} A_{l}} \\
\mathbf{x}_{\text {aggregate investment }}=\frac{\sum_{l \in J_{1}}\left(A_{l}-\mathbf{e}^{\top}(a \mathbf{T}+b \mathbf{D})\right)\left(\frac{\boldsymbol{\Omega}^{-1} \mathbf{e}}{\mathbf{e}^{\top} \boldsymbol{\Omega}^{-1} \mathbf{e}}+\lambda_{I}\left(\boldsymbol{\Omega}^{-1} \mathbf{m}-\frac{\mathbf{e}^{\top} \boldsymbol{\Omega}^{-1} \mathbf{m}}{\left.\left.\mathbf{e}^{\top} \boldsymbol{\Omega}^{-1} \mathbf{e}^{-1} \mathbf{e}\right)\right)}\right.\right.}{\sum_{l \in J_{1}}\left(A_{l}-\mathbf{e}^{\top}(a \mathbf{T}+b \mathbf{D})\right)}
\end{gathered}
$$

Between 2007 Q1 and 2008 Q1, the increase of the optimal euro share and the decline of the optimal dollar share in the investment tranche (Figure 9) are in line wiht the increasing returns of euro and the decreasing returns of dollar, as shown in Figure 5. The trend reversed after 2008.

Figure 9: The Optimal Shares of EUR and USD in the Aggregate Liquidity Tranche and Investment Tranche (2006 - 2014)
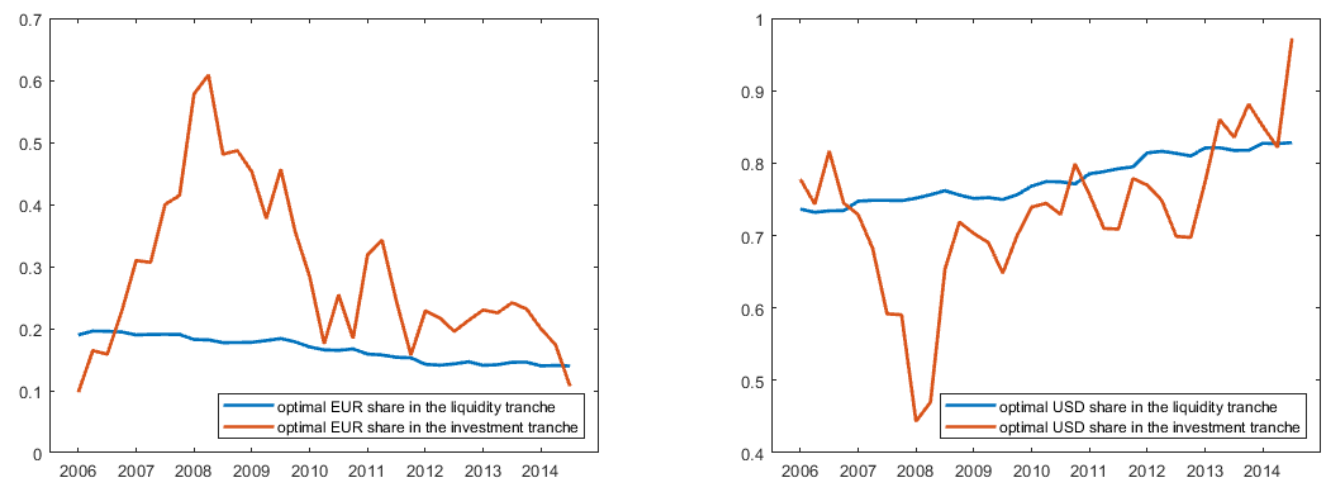

Sources: Federal Reserve Bank of St. Louis; Gopinath (2016); Haver; IMF COFER and DOTS; UNCTAD; World Bank International Debt Statistics; and authors' calculations.

\subsection{The size of the liquidity tranche included in the reduced- form analysis}

Some hypothesis can be tested based on the relative size of the liquidity tranche, $\frac{\sum_{l \in J_{1}} \mathbf{e}^{\boldsymbol{\top}}(a \mathbf{T}+b \mathbf{D})+\sum_{l \in J_{2}} A_{l}}{\sum_{l \in J} A_{l}}$.

First, we expect that the larger the relative liquidity tranche size, the larger effect the 
currency compositions of imports invoicing and short-term external debt on the currency composition of FX reserves. To test the hypothesis, we interact the relative size of liquidity tranche with the currency compositions of imports invoicing and short-term external debt, and the weighted average of the currency composition in imports invoicing and short-term external debt, and include them as control variables in the regressions in Section 2.5. As expected, the sign of the interaction terms are positive and statistically significant (Columns (1), (3), and (4) in Table 3).

Second, we expect that, the larger the relative size of liquidity tranche, the smaller effect the exchange rate returns on the currency composition of FX reserves. To test it, we interact the relative size of liquidity tranche with the exchange rate returns. As expected, the sign of the interaction terms are negative and statistically significant (Columns (1)-(4) in Table 3).

The coefficients of the interaction terms in Table 3 also indicate that the estimated relative size of liquidity tranche and our estimates of the model's parameters are robust.

\section{The RMB as Reserve Currency}

\subsection{The liquidity of the government bond market and the con- vertibility of the currency}

When central banks decide whether to include one new currency in their FX reserves, the liquidity of that currency issuer's government bond market and the ease of convertibility of that currency are important factors. As an example, Christian Vallence's "Foreign Exchange Reserves and the Reserve Bank's Balance Sheet" describes the reserve management practice of the Reserve Bank of Australia (Vallence, 2012),

"The Bank first identifies eligible reserve currencies based on several criteria, including the ease of convertibility of the currency into US and/or Australian dollars, and whether the currency has underlying government bond markets that are sufficiently liquid for intervention purposes, and the sovereign

(C) International Monetary Fund. Not for Redistribution 
Table 3. Results of the Reduced-form Regression with the Relative Size of Liquidity Tranche Included

\begin{tabular}{|c|c|c|c|c|}
\hline & $(1)$ & $(2)$ & $(3)$ & $(4)$ \\
\hline \multirow[t]{2}{*}{ imports invoicing } & $0.631^{* * *}$ & & & \\
\hline & $(5.06)$ & & & \\
\hline \multirow[t]{2}{*}{ ST external debt denomination } & & $0.383^{* * *}$ & & \\
\hline & & $(7.23)$ & & \\
\hline \multirow[t]{2}{*}{ imports invoicing and ST external debt denomination } & & & $0.500^{* * *}$ & $0.500^{* * *}$ \\
\hline & & & $(8.26)$ & $(8.24)$ \\
\hline \multirow[t]{2}{*}{ average return } & $658.0^{* * *}$ & $455.8^{* *}$ & $551.0^{* * *}$ & $590.2^{* * *}$ \\
\hline & $(3.00)$ & $(2.57)$ & $(3.05)$ & $(2.83)$ \\
\hline \multirow[t]{2}{*}{ return volatility } & -1.547 & 2.340 & 1.340 & 2.066 \\
\hline & $(-0.62)$ & $(1.15)$ & $(0.65)$ & $(0.73)$ \\
\hline \multirow[t]{2}{*}{ government bond spread } & & & & 4.384 \\
\hline & & & & $(0.38)$ \\
\hline \multirow[t]{2}{*}{ imports invocing $\times$ rel liquidity size } & $0.0913^{*}$ & & & \\
\hline & $(1.74)$ & & & \\
\hline \multirow[t]{2}{*}{ ST external debt denomination $\times$ rel liquidity size } & & 0.0307 & & \\
\hline & & $(0.67)$ & & \\
\hline \multirow[t]{2}{*}{ imports and ST external debt $\times$ rel liquidity size } & & & $0.0726^{*}$ & $0.0709^{*}$ \\
\hline & & & $(1.77)$ & $(1.71)$ \\
\hline \multirow[t]{2}{*}{ average return $\times$ rel liquidity size } & $-717.1^{* * *}$ & $-416.4^{* *}$ & $-566.4^{* * *}$ & $-614.6^{* *}$ \\
\hline & $(-2.82)$ & $(-2.03)$ & $(-2.71)$ & $(-2.50)$ \\
\hline \multirow[t]{2}{*}{ const } & $0.0883^{* * *}$ & $0.151^{* * *}$ & $0.105^{* * *}$ & $0.101^{* * *}$ \\
\hline & $(2.63)$ & $(11.33)$ & $(5.92)$ & $(4.84)$ \\
\hline$N$ & 144 & 144 & 144 & 144 \\
\hline within R-square & 0.3024 & 0.5544 & 0.5254 & 0.5259 \\
\hline \multicolumn{5}{|l|}{$t$ statistics in parentheses. } \\
\hline${ }^{*} p<0.10,{ }^{* *} p<0.05,{ }^{* * *} p<0.01$ & & & & \\
\hline
\end{tabular}


issuer is of high credit quality."

We use the bid-ask spread of the government bonds to measure the liquidity of the government bond markets. Figure 10 shows the mean (over time) of the daily bid-ask spread of the government bond of the eurozone, Japan, UK, US, China, using the latest oneyear sample up to each quarter. We can observe that China's government bonds are less liquid than other reserve currency issuers' government bonds, although the liquidity has improved since the first half of 2018 (Figure 10).

Figure 10: Bid-ask Spread of 2Y Government Bonds (2005 Q4 - 2018 Q2)

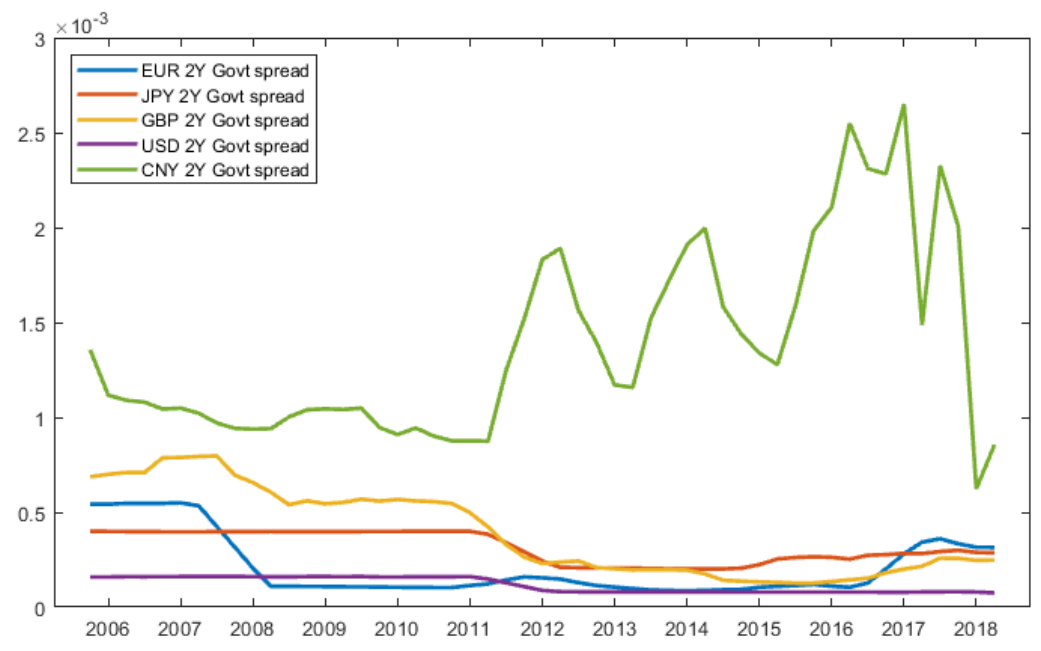

Sources: Bloomberg Finance L.P.; and authors' calculations.

The bid-ask spread of each reserve currency versus domestic currency can be used to measure the transaction cost in the forex market (the ease of convertibility). Figure 11 shows the mean (over time) of the daily bid-ask spread of EUR, JPY, GBP, USD, and RMB (onshore market) versus the domestic currency of China, Saudi Arabia, Russia, India, Brazil, averaged for these five large emerging market economies, using the latest one-year sample up to each quarter. We can see that the transaction cost of RMB is above those of other reserve currencies in most times.

\subsection{The RMB as reserve currency under different scenarios}

It is expected that China will gradually enhance capital account convertibility, and the share of RMB in central banks' FX reserves will further increase from the current level of 
Figure 11: Bid-ask Spread of Exchange Rates (2005 Q3 - 2018 Q2)

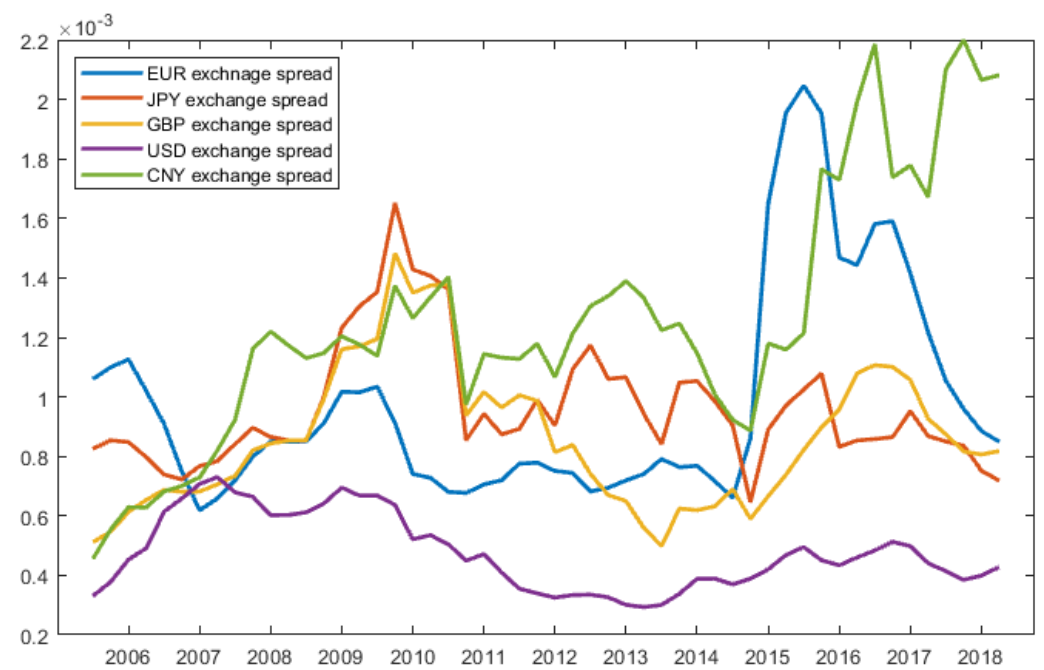

Sources: Bloomberg Finance L.P.; and authors' calculations.

around 2 percent. Over 60 central banks or monetary authorities hold RMB reserves (Yi, 2018). Based on our estimates in Section 6, we can estimate the share of RMB in central banks' FX reserves under different hypothetical scenarios.

The exchange rate risk and returns of RMB affects its share in the aggregate FX reserves through its share in the investment tranche. ${ }^{25}$ As a benchmark, for each country in our sample excluding China, we set the RMB's expected return, variance and covariances with EUR, JPY, GBP, USD to be the average of SDR currencies' corresponding parameters. The currency-specific fixed term of RMB in equation (2) is set to be the average of SDR currencies' estimated fix terms. ${ }^{26}$ Our analysis can be made in different scenarios, using equation (2) with $\Omega_{t}, \mathbf{m}_{t}, \mathbf{T}_{t}, \mathbf{D}_{t}$ augmented to include RMB terms. We do the analysis for the last period in our sample, 2014 Q4.

\section{The growing share of RMB in imports invoicing and short-term external debt}

Holding other things constant, the increase in RMB's share in imports invoicing and

\footnotetext{
${ }^{25}$ The analysis of the exchange rate return and risk of the free floating RMB is beyond the scope of this paper.

${ }^{26}$ See footnote 24 .
} 
short-term external debt will increase RMB's share in the liquidity tranche, thus in the aggregate FX reserves. This can be observed from Figure 12. If the share of RMB in imports invoicing and short-term external debt are 50 percent, RMB's share in FX reserves of developing countries including China would be around 15 percent; ${ }^{27}$ RMB's share in FX reserves of developing countries excluding China would be around 35 percent.

Figure 12: The Estimated Share of RMB in FX Reserves versus Those in Imports Invoicing (0-0.5) and Short-term External Debt (0-0.5): China Included (left) and Excluded (right)
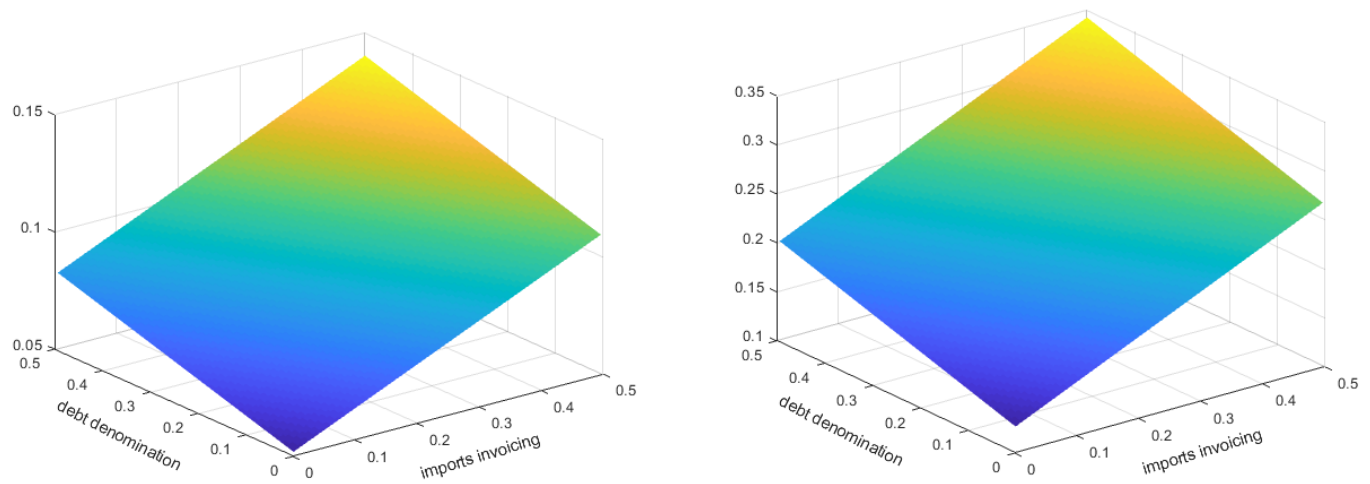

Sources: Federal Reserve Bank of St. Louis; Gopinath (2016); Haver; IMF COFER and DOTs; UNCTAD; World Bank International Debt Statistics; and authors' calculations.

\section{The trend of RMB to be reference currency}

For a sample comprising emerging-market economies, Subramanian and Kessler (2013) find that between 2010 and 2013, RMB has increasingly become a reference currency, which they define as one that exhibits a high degree of co-movement with the domestic currencies of the reserve holders; the rise of the RMB as a reference currency is especially prominent in East Asia. ${ }^{28}$ McCauley and Chan (2014), and Ito et al. (2015) point out that, for China's trading partners, both changing trade invoicing and currency movements

\footnotetext{
${ }^{27}$ We first adopt equation (2) to calculate the RMB's share in FX reserves of developing countries excluding China, as RMB's share in China's FX reserves is 0; then we can use the aggregate FX reserves of China and developing countries excluding China to calculate RMB's share in FX reserves of developing countries including China.

${ }^{28} \mathrm{As}$ a reference currency outside Asia, the RMB has increased its presence from 7 to 11 (out of 42) countries in their sample.
} 
could make RMB more attractive for reserve managers. ${ }^{29}$

Using our estimates, we estimate the share of RMB under the scenarios that RMB has different levels of co-movement with the domestic currencies of our sample countries, excluding China itself. If RMB has a stronger co-movement with our sample countries' domestic currencies, then from those countries' perspective, RMB is more like a risk-free asset and has a lower variance. Thus for each of our sample countries excluding China, we adjust the variance of RMB's exchange rate return we set above; the covariances between between RMB and EUR, JPY, GBP, USD are adjusted accordingly, assuming the correlation parameters are the same as before. A smaller variance of RMB implies the status of RMB as a reference currency is more prominent.

Figure 13 shows the estimated share of RMB in FX reserves versus the return of RMB (vary between $0.1 \times 10^{-5}$ and $10 \times 10^{-5}$ ) 30 and the average of variance of RMB among our sample countries excluding China (vary between $1.7 \times 10^{-5}$ and $\left.24 \times 10^{-5}\right)^{31}$. We can see a more prominent status as reference currency could lead to higher RMB's share in FX reserves; the magnitude of the effect is more significant when RMB has a relatively higher return.

\section{Conclusion}

The way central banks manage their reserves have evolved over the past decades, reflecting changes in both the economic and the broader institutional environment. Central

\footnotetext{
${ }^{29}$ The dollar zone weight (the weighted average all other economies' dollar zone weight, similar with what we did in section 2.3, using GDP share as weight) and share in export invoicing are highly correlated, their reduced-form analysis finds that both trade invoicing and currency movements drive changing official reserve composition, but they can not distinguish the effect of these two factors on the currency composition due to data limitation.

${ }^{30}$ Estimated using the sample data from 2007 Q4 to 2014 Q4, the averages of returns among our sample countries including China are around $7.18 \times 10^{-5}$ for EUR, $5.44 \times 10^{-5}$ for JPY, $9.26 \times 10^{-5}$ for GBP, $12.54 \times 10^{-5}$ for USD respectively.

${ }^{31}$ Estimated using the sample data from 2007 Q4 to 2014 Q4, the averages of variances among our sample countries including China are around $5.23 \times 10^{-5}$ for EUR, $40.71 \times 10^{-5}$ for JPY, $5.98 \times 10^{-5}$ for GBP, $4.97 \times 10^{-5}$ for USD respectively.
} 
Figure 13: The Estimated Share of RMB in FX Reserves versus the Returns of RMB $\left(0.1 \times 10^{-5}-10 \times 10^{-5}\right)$ and the Variances of RMB $\left(1.7 \times 10^{-5}-24 \times 10^{-5}\right)$ :

China included (left) and excluded (right)
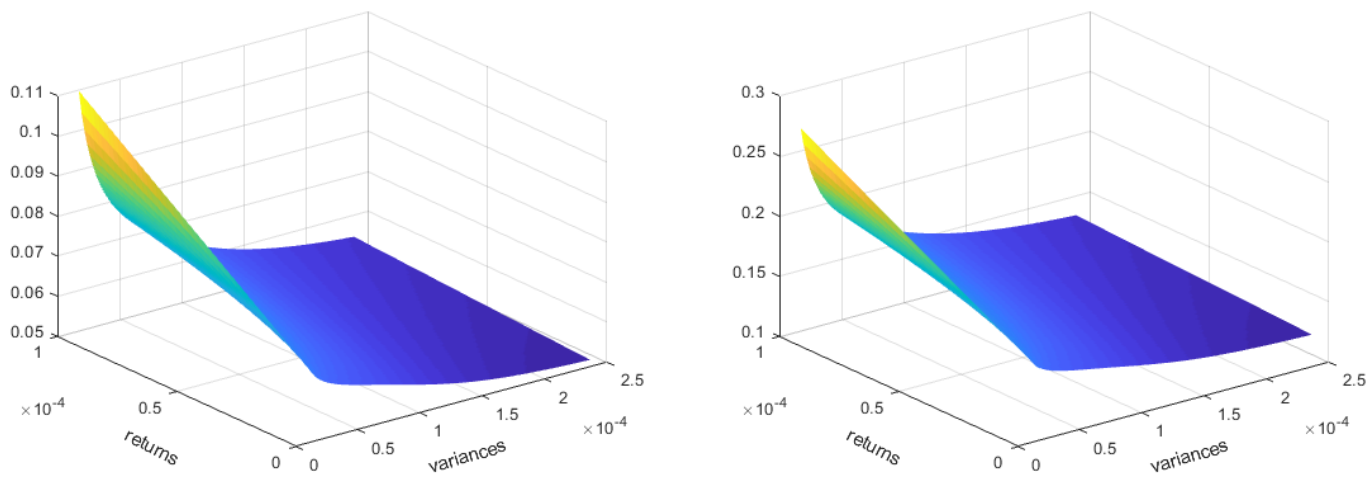

Sources: Federal Reserve Bank of St. Louis; Gopinath (2016); Haver; IMF COFER and DOTS;

UNCTAD; World Bank International Debt Statistics; and authors' calculations.

banks have begun to manage their FX reserves in two or more tranches, to satisfy their FX liquidity needs in the liquidity tranche, and to pursue higher returns subject to some risk constraints in the investment tranche. The appearance of the investment tranche reflects the continuing accumulation of reserves and central banks' growing emphasis on preserving and enhancing the value of the reserves.

In this paper, based on the results of a reduced-form analysis and country-level crosssectional evidence, we present the importance of the currency compositions of imports invoicing and external debt, and exchange rate risk and returns for the currency composition of FX reserves.

Based on central banks' practice and literature review, we have developed a central bank's reserve portfolio choice model to analyze the determinants of the currency composition of FX reserves. Our model formalizes central banks' reserve tranching practice and is estimated to quantify the roles of the currency compositions of imports invoicing and short-term external debt, and risk and returns of exchange rates in determining the currency composition of FX reserves at the aggregate level of central banks. That is a key contribution of our paper, given the absence of structural models in the literature. 
Based on our estimates, we find that compared to 2006 and 2007, there had been a significant increase of the absolute and relative sizes of the investment tranche in emerging and developing countries' FX reserve. After 2008, despite the growth of the aggregate reserve portfolio, the absolute size of the estimated investment tranche has been stable, likely due to the growing liquidity needs associated with the growing imports invoicing and short-term external debt denominated in reserve currencies.

As expected, our estimates show that the investment tranche does have returns objective, while the liquidity tranche does not. The larger the relative size of the liquidity tranche, the more important the effect of the imports invoicing and short-term external debt, and the smaller the effect of reserve currencies' returns on the currency composition of FX reserves. The choice of numeraire is relevant in particular for the investment tranche, while the currency composition of liquidity tranche is determined by the currency composition of FX liquidity needs. There is tendency for central banks to use domestic currency as numeraire to measure the worth of reserve assets, which is the assumption we have used in the estimation.

Finally, we apply our model to estimate the likely paths of share of RMB in FX reserves under different scenarios. The scenarios include a larger share of RMB in countries' imports invoicing and short-term external debt, and the trend of RMB becoming reference currency for other countries. The exercise helps to shed light on the potential status of the RMB as an international currency. 


\section{Reference}

Borio, C., G. Galati, and A. Heath, 2008. FX Reserve Management: Trends and Challenges. BIS Papers No. 40.

Boorman, J. and S. Ingves, 2001. Issues in Reserves Adequacy and Management. October 15, 2001, IMF.

Central Bank of Chile, 2006, Management of foreign exchange reserves at the Central Bank of Chile.

Central Bank of Chile, 2012, Management of foreign exchange reserves at the Central Bank of Chile.

Chen, H. Y., W. S. Peng, and C. Shu, 2011. The Potential of Renminbi as an International

Currency. In: Currency Internationalisation: Lessons from the Global Financial Crisis and Prospects for the Future in Asia and the Pacific, Proceedings of Bank of Korea/BIS seminar on Currency Internationalisation, Seoul, March 19-20, 2009, BIS Papers No. 61, December, 125-148.

Chinn, M. and J. Frankel, 2005. Will the Euro Eventually Surpass the Dollar as Leading International Reserve Currency? In: Clarida, R. (Ed.), G7 Current Account Imbalances: Sustainability and Adjustment. University of Chicago Press, Chicago, IL.

De Leon, J., 2003. How the Bank of Canada Manages Reserves. In: Pringle, R. and N. Carver (Eds.), How Countries Manage Reserve Assets. Central Banking Publications, London, UK.

Dooley, M. P., S. Lizondo, and D. Mathieson, 1989. The Currency Composition of Foreign Exchange Reserves. International Monetary Fund Staff Paper 36 (2), 385-434.

Dooley, M.P., D. Folkerts-Landau, and P.M. Garber, 2003. An Essay on the Revived Bretton Woods System. Working Paper No. 9971. NBER.

Dooley, M. P., D. Folkerts-Landau, and P.M. Garber, 2004. Interest Rates, Exchange Rates and International Adjustment. Working Paper No. 10727. NBER.

Eichengreen, B., 1998. The Euro as a Reserve Currency. Journal of the Japanese and International Economies 12 (4), 483-506.

Eichengreen, B. and D. Mathieson, 2000. The Currency Composition of Foreign Exchange Reserves: Retrospect and Prospect. International Monetary Fund Working Paper 00/131. European Central Bank (ECB), 2004. Risk Management for Central Bank Foreign Reserves. In: Bernadell, C., P. Cardon, F.X. Coche, S. Diebold, and J. Manganelli (Eds.). 
European Central Bank, Frankfurt, Germany.

Fisher, S. J. and M. C. Lie, 2004. Asset Allocation for Central Banks: Optimally Combining Liquidity, Duration, Currency and Non-government Risk. In: Bernadell, C., P. Cardon, F. X. Coche, S. Diebold, and J. Manganelli (Eds.), Risk Management for Central Bank Foreign Reserves. European Central Bank, Frankfurt, Germany.

Frankel, J., 1992. On the Dollar. In: Newman, P., M. Milgate, and J. Eatwell (Eds.), the New Palgrave Dictionary of Money and Finance. London: MacMillan Press Reference Books.

Frankel, J., 2012. Internationalization of the RMB and Historical Precedents. Journal of Economic Integration, 2012, vol.27, no.3, pp. 329-365.

Frankel, J. and S. J. Wei, 1994. Yen Bloc or Dollar Bloc? Exchange Rate Policies of the East Asian Economies. In: Ito, T and A. O. Krueger (Eds.), Macroeconomic Linkages: Savings, Exchange Rates and Capital Flows. Chicago: University of Chicago Press.

Frankel, J. and S. J. Wei, 2007. Assessing China's Exchange Rate Regime. Economic Policy 22, no. 51: 575-614.

Gopinath, G., 2016. The International Price System. Jackson Hole Symposium Proceedings.

Gourinchas, P. O., H. Rey, and N. Govillot, 2010. Exorbitant Privilege and Exorbitant Duty. IMES Discussion Paper Series 10-E-20, Institute for Monetary and Economic Studies, Bank of Japan.

He, Z. G., A. Krishnamurthy, and K. Milbradt, 2018. A Model of Safe Asset Determination. American Economic Review, forthcoming.

International Monetary Fund, 2001. Issues in Reserves Adequacy and Management. IMF Policy Paper.

International Monetary Fund, 2011. Assessing Reserve Adequacy. IMF Policy Paper. Ito, H., R. McCauley, and T. Chan, 2015. Emerging Market Currency Composition of Reserves, Denomination of Trade and Currency Movements. Emerging Markets Review $25,16-29$.

Kiyotaki, N., K. Matsuyama, and A. Matsui, 1993. Toward a Theory of International Currency. Review of Economic Studies 60: 283-307.

Krugman, P. R., 1984. The International Role of the Dollar: Theory and Prospect. In: Exchange Rate Theory and Practice. NBER. 1984. 
Markowitz, H., 1952. Portfolio Selection, Journal of Finance, 7, 77-91.

McCauley, R., 2008. Choosing the Currency Numeraire in Managing Official Foreign Exchange Reserves. In: Pringle, R. and N. Carver (Eds.), RBS Reserve Management Trends 2008, Central Banking Publications, London.

McCauley, R. and T. Chan, 2014. Currency Movements Drive Reserve Composition. BIS Quarterly Review, December, pp 23-36.

Naameh, Michael, 2003. Reserve Management in Developing Countries. In: Pringle, R. and N. Carver (Eds.), How Countries Manage Reserve Assets. Central Banking Publications, London, UK.

Newey, W. and D. McFadden, 1994. Large Sample Estimation and Hypothesis Testing. In: Engle, R. and D. McFadden (Eds.), Handbook of Econometrics (Vol. 4). New York: Elsevier Science, 2113-2245.

Nugee, J., 2000. Foreign Exchange Reserves Management. In: Handbooks from Centre for Central Banking Studies, Bank of England.

Merkowsky, M. and E. Wolfe, 2015. Recent Enhancements to the Management of Canada's Foreign Exchange Reserves. Bank OF Canada Review.

Papaioannou, E., R. Portes, and G. Siourounis, 2006. Optimal Currency Shares in International Reserves: the Impact of the Euro and The prospects for the Dollar. Journal of Japanese and International Economies 20 (4), 508-547.

Ramaswamy, S., 1999. Reserve Currency Allocation: An Alternative Methodology. BIS Working Paper No. 72.

Reddy, Y. V., 2003. Reserve Management at the Reserve Bank of India. In: Pringle, R. and N. Carver (Eds.), How Countries Manage Reserve Assets. Central Banking Publications, London, UK.

Rey, H., 2001. International Trade and Currency Exchange. Review of Economic Studies 68 (2): 443-64.

Riksbank, 2006. Annual Report 2006.

Royal Bank of Scotland (RBS), 2003. How Countries Manage Reserve Assets. In: Pringle, R. and N. Carver (Eds.). Central Banking Publications, London, UK.

Royal Bank of Scotland (RBS), 2005. Reserve Management Trends. In: Pringle, R. and N. Carver (Eds.). Central Banking Publications, London, UK.

Sharpe, W. F. and L. G. Tint, 1990. Liabilities - A New Approach, Journal of Portfolio 
Management, Winter 1990, 5-10.

Subramanian, A. and M. Kessler (2013). The Renminbi Bloc is Here: Asia Down, Rest of the World to Go? Peterson Institute for International Economics Working Paper Series, WP 12-19.

Vallence, C., 2012. Foreign Exchange Reserves and the Reserve Bank's Balance Sheet. Reserve Bank of Australia. Bulletin, 57-64, December Quarter 2012.

Yi, Gang, 2018, Creating a New Situation in the Financial Industry in the Comprehensive Deepening of Reform and Opening-up: a Celebration of 40 Years of Reform and Openingup, 70 Years of the People's Bank of China.

Zhang, Z. C., F. Chau, and L. Xie, 2012. Strategic Asset Allocation for Central Bank's Management of Foreign Reserves: A New Approach. University Library of Munich, Germany (MPRA Paper 43654). 


\section{Appendix}

\section{A.1 Central banks' asset allocation problem}

In this appendix, we generalize our model in the main text such that the asset returns are incorporated into consideration. Therefore, different assets denominated in the same foreign currency have different returns and risk. Central banks' choice becomes a broader asset allocation problem.

The central bank decides the share of the asset $j$. The return rate of asset $j$ is $r_{j}$. $\Omega$ is the covariance matrix of assets return rates, $\mathbf{m}$ is the expected return rates of assets. $R_{L}$ is the growth rate of the value of the obligations using domestic currency as numeraire.

The value of the liquidity tranche after one period is

$$
\sum_{j} L x_{L j}\left(1+r_{j}\right)=L\left(1+\sum_{j} x_{L j} r_{j}\right)
$$

The value of the investment tranche after one period is

$$
\sum_{j}(A-L) x_{I j}\left(1+r_{j}\right)=(A-L)\left(1+\sum_{j} x_{I j} r_{j}\right)
$$

The goal of the liquidity tranche is to maximize the surplus under some risk constraints

$$
L \sum_{j} x_{L j} r_{j}-L R_{L}
$$

We have

$$
\operatorname{Var}\left(\sum_{j} x_{L j} r_{j}-R_{L}\right)=\frac{1}{2} \mathbf{x}_{L}^{\top} \mathbf{\Omega x}_{L}-\sum_{j} x_{j} \operatorname{Cov}\left(r_{j}, R_{L}\right)+\operatorname{Var}\left(R_{L}\right)
$$

Thus the central bank's optimization problem is

$$
\max _{\mathbf{x}_{L}} \frac{1}{2} \mathbf{x}_{L}^{\top} \boldsymbol{\Omega} \mathbf{x}_{L}-\gamma^{\top} \mathbf{x}_{L}-\lambda_{L} \mathbf{m}^{\top} \mathbf{x}_{L}
$$

s.t. $\mathbf{e}^{\top} \mathbf{x}_{L}=1$

where $\gamma_{j}=\operatorname{Cov}\left(r_{j}, R_{L}\right)$.

The FOC implies

$$
\mathbf{\Omega x}_{L}-\gamma-\lambda_{L} \mathbf{m}-\mu \mathbf{e}=0
$$

C)International Monetary Fund. Not for Redistribution 
so we have

$$
\begin{gathered}
\boldsymbol{\Omega}^{-1}\left(\gamma+\lambda_{L} \mathbf{m}+\mu \mathbf{e}\right)=\mathbf{x}_{L} \\
\mathbf{e}^{\top} \boldsymbol{\Omega}^{-1}\left(\gamma+\lambda_{L} \mathbf{m}+\mu \mathbf{e}\right)=1
\end{gathered}
$$

then

$$
\begin{gathered}
\mu=\frac{1-\mathbf{e}^{\top} \Omega^{-1}\left(\gamma+\lambda_{L} \mathbf{m}\right)}{\mathbf{e}^{\top} \Omega^{-1} \mathbf{e}} \\
\mathbf{x}_{L}=\Omega^{-1}\left(\gamma+\lambda_{L} \mathbf{m}+\frac{1-\mathbf{e}^{\top} \Omega^{-1}\left(\gamma+\lambda_{L} \mathbf{m}\right)}{\mathbf{e}^{\top} \Omega^{-1} \mathbf{e}} \mathbf{e}\right) \\
=\frac{\Omega^{-1} \mathbf{e}}{\mathbf{e}^{\top} \Omega^{-1} \mathbf{e}}+\lambda_{L}\left(\Omega^{-1} \mathbf{m}-\frac{\mathbf{e}^{\top} \Omega^{-1} \mathbf{m}}{\mathbf{e}^{\top} \Omega^{-1} \mathbf{e}} \Omega^{-1} \mathbf{e}\right)+\left(\Omega^{-1} \gamma-\frac{\mathbf{e}^{\top} \Omega^{-1} \gamma}{\mathbf{e}^{\top} \Omega^{-1} \mathbf{e}} \Omega^{-1} \mathbf{e}\right)
\end{gathered}
$$

where $\frac{\boldsymbol{\Omega}^{-1} \mathbf{e}}{\mathbf{e}^{\top} \boldsymbol{\Omega}^{-1} \mathbf{e}}+\left(\boldsymbol{\Omega}^{-1} \gamma-\frac{\mathbf{e}^{\top} \boldsymbol{\Omega}^{-1} \gamma}{\mathbf{e}^{\top} \boldsymbol{\Omega}^{-1} \mathbf{e}} \boldsymbol{\Omega}^{-1} \mathbf{e}\right)$ is the minimum variance portfolio $\left(\lambda_{L}=0\right)$.

$R_{L}=\sum_{i} y_{i} R_{i}, \gamma=\sum_{i} y_{i} \gamma^{i}$, where $\gamma_{j}^{i}=\operatorname{Cov}\left(r_{j}, R_{i}\right)$, namely

$$
\gamma=\left(\begin{array}{c}
\operatorname{Cov}\left(r_{1}, R_{1}\right), \operatorname{Cov}\left(r_{1}, R_{2}\right), \ldots \\
\operatorname{Cov}\left(r_{2}, R_{1}\right), \operatorname{Cov}\left(r_{2}, R_{2}\right), \ldots \\
\ldots
\end{array}\right)\left(\begin{array}{l}
y_{1} \\
y_{2} \\
\ldots
\end{array}\right)=\mathbf{S y}
$$

The model in the main context is a special case where $\mathbf{S}$ is the covariance matrix of the currencies' return rates,

$$
\gamma=\left(\begin{array}{c}
\operatorname{Cov}\left(R_{1}, R_{1}\right), \operatorname{Cov}\left(R_{1}, R_{2}\right), \ldots \\
\operatorname{Cov}\left(R_{2}, R_{1}\right), \operatorname{Cov}\left(R_{2}, R_{2}\right), \ldots \\
\ldots
\end{array}\right)\left(\begin{array}{l}
y_{1} \\
y_{2} \\
\ldots
\end{array}\right)=\Omega \mathbf{y}
$$

The goal for the investment tranche is to maximize the returns under some risk budget. It's equivalent to maximize $1+\sum_{j} x_{I j} r_{j}$. The central bank's optimization problem for the investment tranche is

$$
\min _{\mathbf{x}_{I}} \frac{1}{2} \mathbf{x}_{I}^{\top} \Omega \mathbf{x}_{I}-\lambda_{I} \mathbf{m}^{\top} \mathbf{x}_{I}
$$

s.t. $\mathbf{e}^{\top} \mathbf{x}_{I}=1$

The solution is

$$
\mathbf{x}_{I}=\frac{\Omega^{-1} \mathbf{e}}{\mathbf{e}^{\top} \Omega^{-1} \mathbf{e}}+\lambda_{I}\left(\Omega^{-1} \mathbf{m}-\frac{\mathbf{e}^{\top} \Omega^{-1} \mathbf{m}}{\mathbf{e}^{\top} \Omega^{-1} \mathbf{e}} \Omega^{-1} \mathbf{e}\right)
$$

If $L \geq A$, the whole portfolio is the liquidity tranche $\mathbf{x}=\mathbf{x}_{L}$. Otherwise

$$
\mathbf{x}=\frac{L \mathbf{x}_{L}+(A-L) \mathbf{x}_{I}}{A}=\mathbf{x}_{I}+\frac{L}{A}\left(\mathbf{x}_{L}-\mathbf{x}_{I}\right)
$$

C)International Monetary Fund. Not for Redistribution 
$=\frac{\Omega^{-1} \mathbf{e}}{\mathbf{e}^{\top} \Omega^{-1} \mathbf{e}}+\lambda_{I}\left(\boldsymbol{\Omega}^{-1} \mathbf{m}-\frac{\mathbf{e}^{\top} \boldsymbol{\Omega}^{-1} \mathbf{m}}{\mathbf{e}^{\top} \boldsymbol{\Omega}^{-1} \mathbf{e}} \boldsymbol{\Omega}^{-1} \mathbf{e}\right)+\frac{L}{A}\left(\boldsymbol{\Omega}^{-1} \gamma-\frac{\mathbf{e}^{\top} \boldsymbol{\Omega}^{-1} \gamma}{\mathbf{e}^{\top} \boldsymbol{\Omega}^{-1} \mathbf{e}} \boldsymbol{\Omega}^{-1} \mathbf{e}+\left(\lambda_{L}-\lambda_{I}\right)\left(\boldsymbol{\Omega}^{-1} \mathbf{m}-\frac{\mathbf{e}^{\top} \boldsymbol{\Omega}^{-1} \mathbf{m}}{\mathbf{e}^{\top} \boldsymbol{\Omega}^{-1} \mathbf{e}} \boldsymbol{\Omega}^{-1} \mathbf{e}\right)\right)$

The obligations of foreign currencies depend on the imports payment and short-term external debt service,

$$
L \mathbf{y}=a \mathbf{T}+b \mathbf{D}
$$

The aggregate obligation and the size of the liquidity tranche are

$$
\begin{gathered}
L=\mathbf{e}^{\top} L \mathbf{y}=\mathbf{e}^{\top}(a \mathbf{T}+b \mathbf{D}) \\
\mathbf{y}=\frac{a \mathbf{T}+b \mathbf{D}}{\mathbf{e}^{\top}(a \mathbf{T}+b \mathbf{D})} \\
l \in \begin{cases}J_{1} & \text { if } \mathbf{e}^{\top}\left(a \mathbf{T}_{l}+b \mathbf{D}_{l}\right)<A_{l} \\
J_{2} & \text { if } \mathbf{e}^{\top}\left(a \mathbf{T}_{l}+b \mathbf{D}_{l}\right) \geq A_{l}\end{cases}
\end{gathered}
$$

The asset composition of central bank $l \in J_{1}$ are,

$$
\begin{gathered}
\mathbf{X}=\frac{\boldsymbol{\Omega}^{-1} \mathbf{e}}{\mathbf{e}^{\top} \boldsymbol{\Omega}^{-1} \mathbf{e}}+\lambda_{I}\left(\boldsymbol{\Omega}^{-1} \mathbf{m}-\frac{\mathbf{e}^{\top} \boldsymbol{\Omega}^{-1} \mathbf{m}}{\mathbf{e}^{\top} \boldsymbol{\Omega}^{-1} \mathbf{e}} \boldsymbol{\Omega}^{-1} \mathbf{e}\right)+\frac{1}{A}\left(a\left(\boldsymbol{\Omega}^{-1} \mathbf{S T}-\frac{\boldsymbol{\Omega}^{-1} \mathbf{e}}{\mathbf{e}^{\top} \boldsymbol{\Omega}^{-1} \mathbf{e}} \mathbf{e}^{\top} \boldsymbol{\Omega}^{-1} \mathbf{S T}\right)\right. \\
\left.+b\left(\boldsymbol{\Omega}^{-1} \mathbf{S D}-\frac{\boldsymbol{\Omega}^{-1} \mathbf{e}}{\mathbf{e}^{\top} \boldsymbol{\Omega}^{-1} \mathbf{e}} \mathbf{e}^{\top} \boldsymbol{\Omega}^{-1} \mathbf{S D}\right)\right)+\frac{1}{A}\left(\lambda_{L}-\lambda_{I}\right)\left(\boldsymbol{\Omega}^{-1} \mathbf{m}-\frac{\mathbf{e}^{\top} \boldsymbol{\Omega}^{-1} \mathbf{m}}{\mathbf{e}^{\top} \boldsymbol{\Omega}^{-1} \mathbf{e}} \boldsymbol{\Omega}^{-1} \mathbf{e}\right) \mathbf{e}^{\top}(a \mathbf{T}+b \mathbf{D})
\end{gathered}
$$

The asset composition of central bank $l \in J_{2}$ are,

$$
\begin{gathered}
\mathbf{x}=\frac{\Omega^{-1} \mathbf{e}}{\mathbf{e}^{\top} \boldsymbol{\Omega}^{-1} \mathbf{e}}+\lambda_{L}\left(\boldsymbol{\Omega}^{-1} \mathbf{m}-\frac{\mathbf{e}^{\top} \boldsymbol{\Omega}^{-1} \mathbf{m}}{\mathbf{e}^{\top} \boldsymbol{\Omega}^{-1} \mathbf{e}} \boldsymbol{\Omega}^{-1} \mathbf{e}\right)+\left(\boldsymbol{\Omega}^{-1} \mathbf{S y}-\frac{\mathbf{e}^{\top} \boldsymbol{\Omega}^{-1} \mathbf{S} \mathbf{y}}{\mathbf{e}^{\top} \boldsymbol{\Omega}^{-1} \mathbf{e}} \boldsymbol{\Omega}^{-1} \mathbf{e}\right) \\
=\frac{\boldsymbol{\Omega}^{-1} \mathbf{e}}{\mathbf{e}^{\top} \boldsymbol{\Omega}^{-1} \mathbf{e}}+\lambda_{L}\left(\boldsymbol{\Omega}^{-1} \mathbf{m}-\frac{\mathbf{e}^{\top} \boldsymbol{\Omega}^{-1} \mathbf{m}}{\mathbf{e}^{\top} \boldsymbol{\Omega}^{-1} \mathbf{e}} \boldsymbol{\Omega}^{-1} \mathbf{e}\right)+\left(\boldsymbol{\Omega}^{-1} \mathbf{S} \frac{a \mathbf{T}+b \mathbf{D}}{\mathbf{e}^{\top}(a \mathbf{T}+b \mathbf{D})}-\frac{\boldsymbol{\Omega}^{-1} \mathbf{e}}{\mathbf{e}^{\top} \boldsymbol{\Omega}^{-1} \mathbf{e}} \mathbf{e}^{\top} \boldsymbol{\Omega}^{-1} \mathbf{S} \frac{a \mathbf{T}+b \mathbf{D}}{\mathbf{e}^{\top}(a \mathbf{T}+b \mathbf{D})}\right)
\end{gathered}
$$

Aggregating the optimal choice of central banks $l \in J_{1}$ and $l \in J_{2}$, assuming each central bank has the same $\lambda_{L}, \lambda_{I}, a, b$,

$$
\begin{gathered}
\mathbf{x}_{\text {aggregate }}\left(\mathbf{A}, \boldsymbol{\Omega}, \mathbf{S}, \mathbf{m}, \mathbf{T}, \mathbf{D}, a, b, \lambda_{I}, \lambda_{L}\right):=\frac{\sum_{l \in J} A_{l} \mathbf{x}_{l}}{\sum_{l \in J} A_{l}}=\frac{\sum_{l \in J} A_{l} \frac{\boldsymbol{\Omega}_{l}^{-1} \mathbf{e}}{\mathbf{e}^{\top} \boldsymbol{\Omega}_{l}^{-1} \mathbf{e}}}{\sum_{l \in J} A_{l}} \\
+a \frac{\sum_{l \in J_{1}}\left(\boldsymbol{\Omega}_{l}^{-1} \mathbf{S}_{l} \mathbf{T}_{l}-\frac{\boldsymbol{\Omega}_{l}^{-1} \mathbf{e}}{\mathbf{e}^{\top} \boldsymbol{\Omega}_{l}^{-1} \mathbf{e}} \mathbf{e}^{\top} \boldsymbol{\Omega}_{l}^{-1} \mathbf{S}_{l} \mathbf{T}_{l}\right)}{\sum_{l \in J} A_{l}}+b \frac{\sum_{l \in J_{1}}\left(\boldsymbol{\Omega}_{l}^{-1} \mathbf{S}_{l} \mathbf{D}_{l}-\frac{\boldsymbol{\Omega}_{l}^{-1} \mathbf{e}}{\mathbf{e}^{\top} \boldsymbol{\Omega}_{l}^{-1} \mathbf{e}} \mathbf{e}^{\top} \boldsymbol{\Omega}_{l}^{-1} \mathbf{S}_{l} \mathbf{D}_{l}\right)}{\sum_{l \in J} A_{l}} \\
+\frac{\sum_{l \in J_{2}} A_{l}\left(\boldsymbol{\Omega}_{l}^{-1} \mathbf{S}_{l} \frac{a \mathbf{T}_{l}+b \mathbf{D}_{l}}{\mathbf{e}^{\top}\left(a \mathbf{T}_{l}+b \mathbf{D}_{l}\right)}-\frac{\mathbf{e}^{\top} \boldsymbol{\Omega}_{l}^{-1} \mathbf{s}_{l}}{\mathbf{e}^{\top} \boldsymbol{\Omega}_{l}^{-1} \mathbf{e}} \frac{a \mathbf{T}_{l}+b \mathbf{D}_{l}}{\mathbf{e}^{\top}\left(a \mathbf{T}_{l}+b \mathbf{D}_{l}\right)} \boldsymbol{\Omega}_{l}^{-1} \mathbf{e}\right)}{\sum_{l \in J} A_{l}} \\
+\lambda_{I}\left(\frac{\sum_{l \in J_{1}} A_{l}\left(\boldsymbol{\Omega}_{l}^{-1} \mathbf{m}_{l}-\frac{\mathbf{e}^{\top} \boldsymbol{\Omega}_{l}^{-1} \mathbf{m}_{l}}{\mathbf{e}^{\top} \boldsymbol{\Omega}_{l}^{-1} \mathbf{e}} \mathbf{\Omega}_{l}^{-1} \mathbf{e}\right)}{\sum_{l \in J} A_{l}}-\frac{\sum_{l \in J_{1}}\left(\boldsymbol{\Omega}_{l}^{-1} \mathbf{m}_{l}-\frac{\mathbf{e}^{\top} \boldsymbol{\Omega}_{l}^{-1} \mathbf{m}_{l}}{\mathbf{e}^{\top} \boldsymbol{\Omega}_{l}^{-1} \mathbf{e}} \boldsymbol{\Omega}_{l}^{-1} \mathbf{e}\right) \mathbf{e}^{\top}\left(a \mathbf{T}_{l}+b \mathbf{D}_{l}\right)}{\sum_{l \in J} A_{l}}\right)
\end{gathered}
$$




$$
+\lambda_{L}\left(\frac{\sum_{l \in J_{1}}\left(\boldsymbol{\Omega}_{l}^{-1} \mathbf{m}_{l}-\frac{\mathbf{e}^{\top} \boldsymbol{\Omega}_{l}^{-1} \mathbf{m}_{l}}{\mathbf{e}^{\top} \boldsymbol{\Omega}_{l}^{-1} \mathbf{e}} \boldsymbol{\Omega}_{l}^{-1} \mathbf{e}\right) \mathbf{e}^{\boldsymbol{\top}}\left(a \mathbf{T}_{l}+b \mathbf{D}_{l}\right)}{\sum_{l \in J} A_{l}}+\frac{\sum_{l \in J_{2}} A_{l}\left(\boldsymbol{\Omega}_{l}^{-1} \mathbf{m}_{l}-\frac{\mathbf{e}^{\top} \boldsymbol{\Omega}_{l}^{-1} \mathbf{m}_{l}}{\mathbf{e}^{\top} \boldsymbol{\Omega}_{l}^{-1} \mathbf{e}} \boldsymbol{\Omega}_{l}^{-1} \mathbf{e}\right)}{\sum_{l \in J} A_{l}}\right)
$$

As we do not observe the asset composition, we transform the asset composition into the observable currency composition. The assets denomination matrix is defined as $\mathbf{M}$, $M_{i j}=1$ iff asset $j$ is denominated in currency $i$. $\mathbf{M x}_{\text {aggregate }}$ is the currency composition of central banks' aggregate foreign exchange reserves.

Define $\boldsymbol{\Lambda}_{t}:=\left(\mathbf{A}_{t}, \boldsymbol{\Omega}_{t}, \mathbf{S}_{t}, \mathbf{m}_{t}, \mathbf{T}_{t}, \mathbf{D}_{t}\right)$. Assuming $x_{i t}$, the share of currency $i$ in developing countries' foreign exchange reserves in quarter $t$ satisfies

$$
x_{i t}=c_{i}+\beta \mathbf{x}\left(\mathbf{M x}\left(\boldsymbol{\Lambda}_{t}, a, b, \lambda_{I}, \lambda_{L}\right)_{\text {aggregate }}\right)_{i}+\varepsilon_{i t}
$$

Next we can use similar moment conditions as in the main text to get the GMM estimator. The estimation procedure is basically the same as what we did in the main text.

We can extend this model and do the estimation for the case that the assets choice set of the liquidity tranche is restricted to only include the short-dated securities such as T-bills, time deposits, and etc.; while the investment tranche also includes the long-term securities, equities, and etc. 


\section{A.2 Estimation of the asymptotic variance}

Under a set of regularity conditions, ${ }^{32}$

$$
\sqrt{n}(\hat{\theta}-\theta) \stackrel{d}{\rightarrow} N\left(0,\left(\mathbf{G}_{0}^{\top} \mathbf{W}_{0} \mathbf{G}_{0}\right)^{-1} \mathbf{G}_{0}^{\top} \mathbf{W}_{0} \mathbf{S}_{0} \mathbf{W}_{0} \mathbf{G}_{0}\left(\mathbf{G}_{0}^{\top} \mathbf{W}_{0} \mathbf{G}_{0}\right)^{-1}\right)
$$

where

$$
\begin{gathered}
\mathbf{G}_{0}=E\left[\frac{\partial \mathbf{h}_{i}\left(\mathbf{x}_{t}, \boldsymbol{\Lambda}_{t}, \theta\right)}{\partial \theta^{\top}}\right] \\
\mathbf{S}_{0}=E\left[\mathbf{h}_{i}\left(\mathbf{x}_{t}, \boldsymbol{\Lambda}_{t}, \theta\right) \mathbf{h}_{i}\left(\mathbf{x}_{t}, \boldsymbol{\Lambda}_{t}, \theta\right)^{\top}\right] \\
\mathbf{W}_{0}=\operatorname{plim} \mathbf{W}_{n}
\end{gathered}
$$

$\mathbf{G}_{0}, \mathbf{S}_{0}$ can be estimated by $\hat{\mathbf{G}}, \hat{\mathbf{S}}$, where

$$
\begin{gathered}
\hat{\mathbf{G}}=\frac{1}{n} \sum_{i t} \frac{\partial \mathbf{h}_{i}\left(\mathbf{x}_{t}, \boldsymbol{\Lambda}_{t}, \hat{\theta}\right)}{\partial \theta^{\top}} \\
\hat{\mathbf{S}}=\frac{1}{n} \sum_{i t} \mathbf{h}_{i}\left(\mathbf{x}_{t}, \boldsymbol{\Lambda}_{t}, \hat{\theta}\right) \mathbf{h}_{i}\left(\mathbf{x}_{t}, \boldsymbol{\Lambda}_{t}, \hat{\theta}\right)^{\top}
\end{gathered}
$$

$\mathbf{W}_{0}$ is estimated by $\mathbf{W}_{n}$ we calculate in the main text. ${ }^{33}$

$$
\begin{gathered}
\frac{\partial \mathbf{h}_{i}\left(\mathbf{x}_{t}, \boldsymbol{\Lambda}_{t}, \hat{\theta}\right)}{\partial a}=\left(\mathbf{u}_{i}\left(\boldsymbol{\Lambda}_{t}, a, b\right)-\overline{\mathbf{u}}_{i}\left(\boldsymbol{\Lambda}_{t}, a, b\right), 1\right) \beta\left(-\left(\mathbf{u}_{i 2}-\overline{\mathbf{u}}_{i 2}\right)-\left(\mathbf{u}_{i 4}-\overline{\mathbf{u}}_{i 4}\right)-\left(\lambda_{L}-\lambda_{I}\right)\left(\mathbf{u}_{i 7}-\overline{\mathbf{u}}_{i 7}\right)\right) \\
\frac{\partial \mathbf{h}_{i}\left(\mathbf{x}_{t}, \boldsymbol{\Lambda}_{t}, \hat{\theta}\right)}{\partial b}=\left(\mathbf{u}_{i}\left(\boldsymbol{\Lambda}_{t}, a, b\right)-\overline{\mathbf{u}}_{i}\left(\boldsymbol{\Lambda}_{t}, a, b\right), 1\right) \beta\left(-\left(\mathbf{u}_{i 3}-\overline{\mathbf{u}}_{i 3}\right)-\left(\mathbf{u}_{i 5}-\overline{\mathbf{u}}_{i 5}\right)-\left(\lambda_{L}-\lambda_{I}\right)\left(\mathbf{u}_{i 8}-\overline{\mathbf{u}}_{i 8}\right)\right) \\
\frac{\partial \mathbf{h}_{i}\left(\mathbf{x}_{t}, \boldsymbol{\Lambda}_{t}, \hat{\theta}\right)}{\partial \beta}=\left(\mathbf{u}_{i}\left(\boldsymbol{\Lambda}_{t}, a, b\right)-\overline{\mathbf{u}}_{i}\left(\boldsymbol{\Lambda}_{t}, a, b\right), 1\right) \\
\left(1, a, b, a, b, \lambda_{I},\left(\lambda_{L}-\lambda_{I}\right) a,\left(\lambda_{L}-\lambda_{I}\right) b, \lambda_{L}\right)\left(\mathbf{u}_{i}\left(\boldsymbol{\Lambda}_{t}, a, b\right)-\overline{\mathbf{u}}_{i}\left(\boldsymbol{\Lambda}_{t}, a, b\right)\right) \\
\frac{\partial \mathbf{h}_{i}\left(\mathbf{x}_{t}, \boldsymbol{\Lambda}_{t}, \hat{\theta}\right)}{\partial \lambda_{I}}=\left(\mathbf{u}_{i}\left(\boldsymbol{\Lambda}_{t}, a, b\right)-\overline{\mathbf{u}}_{i}\left(\boldsymbol{\Lambda}_{t}, a, b\right), 1\right)(-\beta)\left(\mathbf{u}_{i 6}-\overline{\mathbf{u}}_{i 6}-a\left(\mathbf{u}_{i 7}-\overline{\mathbf{u}}_{i 7}\right)-b\left(\mathbf{u}_{i 8}-\overline{\mathbf{u}}_{i 8}\right)\right) \\
\frac{\partial \mathbf{h}_{i}\left(\mathbf{x}_{t}, \boldsymbol{\Lambda}_{t}, \hat{\theta}\right)}{\partial \lambda_{L}}=\left(\mathbf{u}_{i}\left(\boldsymbol{\Lambda}_{t}, a, b\right)-\overline{\mathbf{u}}_{i}\left(\boldsymbol{\Lambda}_{t}, a, b\right), 1\right)(-\beta)\left(a\left(\mathbf{u}_{i 7}-\overline{\mathbf{u}}_{i 7}\right)+b\left(\mathbf{u}_{i 8}-\overline{\mathbf{u}}_{i 8}\right)+\mathbf{u}_{i 9}-\overline{\mathbf{u}}_{i 9}\right)
\end{gathered}
$$

\footnotetext{
${ }^{32}$ Note the sample moments are not differentiable at $(a, b)$ due to the kinks where $\mathbf{e}^{\boldsymbol{\top}}\left(a \mathbf{T}_{l t}+b \mathbf{D}_{l t}\right)=A_{l}$ for some $l, t$. To be more specific about the kinks, on one side, the change of $(a, b)$ affects the currency composition of the liquidity tranche, and it also has the size effect as the relative size of the liquidity tranche to the investment tranche for central bank $l$ in period $t$ changes; one the other side, as the whole portfolio of central bank $l$ in period $t$ is the liquidity tranche, the size effect goes away. So we are faced with a GMM with nonsmooth moments. The regularity conditions under which the consistency and asymptotic normality can be established can be seen at Newey and McFadden (1994).

${ }^{33}$ If we estimate $\mathbf{W}_{0}$ using $\hat{\theta}$, then our estimate of $\mathbf{W}_{0}$ equals to $\hat{\mathbf{S}}^{-1}$, and our estimate of the asymptotic variance is $\left(\hat{\mathbf{G}}^{\top} \hat{\mathbf{S}}^{-1} \hat{\mathbf{G}}\right)^{-1}$. The quantitative results are similar.
} 